\title{
AdMINISTRACIÓN DE RIESGOS: ANÁLISIS DE UN PROCESO DE ABASTECIMIENTO Y GESTIÓN DE INSUMOS CRÍTICOS
}

RISK MANAGEMENT: PROCESS ANALYSIS OF SUPPLY AND MANAGEMENT OF STRATEGIC INPUTS ${ }^{1}$

Laura Daima ${ }^{2}$

\section{Resumen}

Las organizaciones desarrollan sus actividades en contextos expuestos a infinidad de riesgos que amenazan su continuidad en el tiempo. El presente trabajo de investigación tiene como objetivo la realización de un diagnóstico de la administración de riesgos vinculados al suministro y gestión de insumos críticos para el proceso de producción de fertilizantes de una empresa industrial de la ciudad de Bahía Blanca, con la finalidad de desarrollar una matriz de riesgos que permita su gestión. En función del objetivo, se optó por un enfoque de carácter cualitativo y con propósito descriptivo a través del estudio de caso. Se identificaron los riesgos internos y externos a los que se encuentra expuesto el proceso analizado. Estos fueron presentados en la matriz de riesgos, lo que permitió detectar aquellos que poseen mayor criticidad y que requieren una acción de corrección inmediata. Finalmente, se propusieron acciones de control para gestionarlos.

Palabras claves: gestión de riesgos, matriz de riesgos, organización industrial, procesos críticos

1 Este trabajo constituye un resumen de la tesis desarrollada por la Cra. Laura Daima para optar al título de Magister en Administración (UNS), bajo la dirección de la Mg. Diana Albanese y la Dra. Anahí Briozzo. La misma fue defendida y aprobada el 21-2-2019.

2 Departamento de Ciencias de la Administración, Universidad Nacional del Sur (DCA-UNS). E-mail: daimalaura@hotmail.com 


\section{A bstract}

Organizations develop their activities within a context exposed to considerable risks that threaten their survival over time. The main goal of this research was to make a diagnosis of the risk management related to the supply of strategic inputs in a fertilizer industry located in Bahía Blanca, with the aim of developing a risk matrix that allowed their management. According to the research objectives, a qualitative and descriptive approach was chosen, through the case study. Internal and external risks to which the process was exposed were identified. From the construction of the risk matrix, it was possible to identify graphically the risks that were more critical and required immediate action. Finally, control actions were proposed in order to manage all the risks identified.

Keywords: risk management, risk matrix, industrial organizations, critical processes

JEL: G32, L29 
Administración de riesgos: análisis de un proceso de abastecimiento y gestión de insumos críticos

\section{Introducción}

Las organizaciones desarrollan sus actividades en un contexto expuesto a una infinidad de riesgos tanto internos como externos que amenazan el cumplimiento de sus objetivos. Si bien el riesgo es una característica intrínseca de la actividad empresarial, debe ser gestionado de forma eficiente y efectiva, de manera de no afectar la continuidad de la empresa. Se considera que el riesgo es la exposición a las consecuencias de la incertidumbre, es decir a variaciones respecto de lo planeado o esperado, ya sea una pérdida o un beneficio (Casal, 2010).

Las crisis financieras y fraudes corporativos mundiales operaron como una muestra y advertencia respecto de la vulnerabilidad de los derechos de los accionistas. Atento a ello, es necesario desarrollar una estructura de Gobierno Corporativo que lleve adelante un control adecuado del negocio. La entidad debe ser capaz de analizar sus procesos y priorizarlos en función de su criticidad sobre el cumplimiento de sus objetivos, identificando aquellos controles que sean críticos (AIRMIC, Alarm, IRM; 2010).

En empresas industriales, el proceso productivo es el más relevante junto con el suministro de insumos críticos necesarios para lograr su producción, dado que poseen una relevancia estratégica.

El presente trabajo se desarrolló mediante el análisis de un caso de una empresa industrial argentina dedicada a la producción y comercialización de fertilizantes para la actividad agrícola. La organización cuenta con un complejo productivo significativo dentro del Polo Petroquímico bahiense, en el que se elabora amoníaco y urea granulada. De su proceso de producción se desprende que los insumos indispensables y estratégicos son: gas natural, energía eléctrica y agua industrial.

El objetivo general de esta investigación fue la realización de un diagnóstico de la administración de riesgos vinculados al suministro de insumos críticos para el proceso productivo de la compañía y el desarrollo de una matriz de riesgos que permita su gestión. A tal fin, se definieron los siguientes objetivos particulares: identificar los procesos organizacionales relacionados con el abastecimiento de insumos críticos y su administración, analizar e identificar los riesgos asociados a los procesos organizacionales identificados, valorar los riesgos detectados en función de su probabilidad de ocurrencia e impacto, diseñar una matriz de riesgos para analizar la criticidad de los mismos para la organización y diseñar las acciones de control tendientes a lograr una gestión de dichos riesgos. 
En relación con la Metodología, se optó por una investigación de carácter cualitativo ya que su objetivo es comprender e interpretar el contexto de los acontecimientos en su ambiente natural, tomados tal y como se encuentran, sin que sean reconstruidos o modificados por el investigador (Taylor, 1998). En función de lo descripto, se utilizó el método de estudio de caso, dado que brinda la posibilidad de explicar fenómenos contemporáneos ubicados en su entorno real (Yin, 1989), así como analizar ejemplos concretos de la experiencia de las empresas (Dawson, 1997).

El artículo se estructura de la siguiente manera: en primer lugar, se desarrolla un resumen del marco teórico relacionado con el estudio; a continuación, se describe la metodología adoptada para llevar a cabo la investigación; en el siguiente apartado, se presentan los resultados obtenidos y, por último, se exponen las conclusiones.

\section{M arco teórico}

Los objetivos fundamentales de toda organización son obtener beneficios asociados a su actividad y generar valor para sus accionistas. En el desarrollo de la gestión empresarial, las entidades se enfrentan a diversos riesgos que pueden afectar negativamente el cumplimiento de dichos objetivos.

La mejor forma de afrontar los riesgos es a través de su gestión, la cual debe ser integral y transversal a toda la empresa, de manera de poder anticiparse a los diferentes escenarios que puedan poner en peligro su sostenibilidad en el tiempo.

Las buenas prácticas de Gobierno Corporativo, tales como el establecimiento de sistemas de control interno adecuados y la gestión del riesgo, contribuyen al logro de los objetivos empresariales. Los mismos deben adaptarse a las necesidades del negocio, estrategia y a su perfil de riesgo.

En función de los objetivos de la investigación, en la presente sección se presentarán las temáticas relacionadas a gestión del riesgo, gobierno corporativo, sistema de control interno y matriz de riesgo.

\subsection{G estión del Riesgo}

En la teoría del emprendedor desarrollada por Frank Knight en su libro Risk, Uncertainity and Profit (1921), el autor diferencia por primera vez dos concep- 
Administración de riesgos: análisis de un proceso de abastecimiento y gestión de insumos críticos

tos fundamentales: riesgo e incertidumbre. El primero de ellos es concebido como la aleatoriedad con propiedades conocidas, a las cuales se les puede asignar una probabilidad de ocurrencia, así como también conocer su impacto en relación con la temática analizada. En el caso de la incertidumbre, se define como la aleatoriedad que puede conocerse de manera anticipada, hecho que no ocurre con la probabilidad de ocurrencia ni con su impacto

Knight (1921) subraya el rol fundamental del empresario en la economía al asumir el riesgo de la actividad económica, dado que adquiere los factores de producción a un precio cierto y realiza previsiones sobre la demanda futura, la cual es incierta en cantidad, y el potencial precio que podrá obtener (Castro, Saavedra García y Camarena Adame, 2015). En consecuencia, el aporte fundamental de Knight es la consideración de la incertidumbre y el riesgo como elementos esenciales de la actividad empresarial (Castro et al., 2015).

De acuerdo a Casal (2010): “...Las posibilidades de conocer con anticipación las probabilidades de ocurrencia de los hechos futuros señalan la frontera que divide los dominios del riesgo de los terrenos de la incertidumbre" (p. 161). Dado que la toma de riesgos es una característica inherente en la conducción de negocios, es necesario que los mismos sean administrados dentro de la estructura general de controles de la organización, conocida como "Control Interno".

En función a los objetivos fijados por la organización, los riesgos deben ser identificados, valorados y analizados, de manera de formar una base que determine cómo deben ser administrados. Dado que las condiciones económicas, industriales, de regulación y operación continuarán cambiando en el tiempo, se requieren mecanismos para identificar y tratar los riesgos especiales asociados con el cambio (Mantilla, 2005). De acuerdo a lo expresado, es necesario que el proceso de identificación de riesgos sea un proceso continuo, de manera de lograr la administración adecuada a los nuevos riesgos y a los cambios en los riesgos existentes, antes de que los mismos se materialicen en pérdidas (Comité de Integración Latino Europa - América, 2015).

El compromiso de la Dirección con la Gestión del Riesgo ayuda a evitar, reducir o trasladar esas pérdidas, al contemplar tanto riesgos estratégicos relativos a decisiones fundamentales sobre el futuro de la organización, como riesgos operativos relativos a las actividades diarias (CILEA, 2015).

Para lograr que una efectiva gestión del riesgo sea concebida y comprendida por toda la organización es necesario generar un Marco de Riesgo (Casal, 2010). Dicho marco se encuentra integrado por el compromiso de la Dirección, expresado en políticas organizacionales que componen la filosofía de la administración de riesgo deseada. 


\subsection{G obierno Corporativo}

La variabilidad e inestabilidad del contexto en el cual actúan las organizaciones ha afectado la manera en que deben ser gestionadas, por lo que resulta necesario contar con sistemas de gobierno eficaces y eficientes (Ganga Contreras; Vera Garnica, 2008).

De acuerdo con Casal (2010), el “Gobierno Corporativo" es la forma en que se administran y controlan las sociedades, las cuales reflejan las relaciones de poder entre los accionistas, junta directiva y la gerencia. Un "Buen Gobierno Corporativo" es aquel que cumple con los estándares mínimos adoptados por una sociedad, de manera de garantizar una gerencia recta, los derechos de los accionistas, la fluidez de la información y las relaciones con los grupos de interés (Casal, 2010).

A partir de un "Buen Gobierno Corporativo" se pueden atenuar los problemas de agencia, dado que el dueño de la organización confía su administración a un gestor, mandante, gerente o ejecutivo, con quien tendrá asimetrías de información y funciones de utilidad dispares (Ganga Contreras y Vera Garnica, 2008). Es por ello que resulta necesario confeccionar normas e incentivos a partir de contratos tácitos o explícitos, destinados a alinear el comportamiento del gerente con las pretensiones del dueño, a través de un reparto óptimo de los riesgos en condiciones de incertidumbre (Holmstrom, 1979).

Los fraudes contables-financieros, tales como los sucedidos en el caso Enron en los Estados Unidos en el año 2001 o Parmalat en Europa en el año 2003, pusieron en duda las prácticas financieras y de gobierno de las empresas, así como también la gestión de directores financieros, quienes toman decisiones al límite de la legalidad y la ética (Ganga Contreras et al., 2008).

De allí que surge la necesidad de adoptar políticas y procedimientos dentro de las organizaciones tendientes a lograr un "Buen Gobierno Corporativo", para obtener no sólo la maximización de la riqueza de los accionistas, sino también el ejercicio responsable y transparente en el manejo de la información, velando por los intereses de todos los agentes que interactúan con la organización: accionistas, directores, empleados, acreedores, proveedores y clientes.

El "Buen Gobierno Corporativo" no ha de ser un fin en sí mismo, sino un medio para asegurar la continuidad a largo plazo de la organización. Su proceso de aplicación debe prevalecer en el espíritu de la dirección de la entidad y no reducirse a un acto formal (CILEA, 2015). 


\subsection{Sistemas de Control Interno}

En los años 70, el control interno se centraba en desarrollar mejoras tendientes a lograr su integración con el sistema de auditorías. Su importancia se incrementó entre los años 1973 y 1976 debido a investigaciones derivadas del caso Watergate (Bertani, Polesello Sánchez Mendoza y Troila, 2014). Como respuesta a las investigaciones realizadas, el Congreso estadounidense elaboró un proyecto de ley en 1977, denominado "Foreign Corrupt Practices Act" ("Ley sobre las Prácticas Corruptas Extranjeras"). La ley contiene disposiciones contra sobornos y deja por fuera al control interno de los departamentos de Contabilidad, a cambio de incorporarlo en las Reuniones de Directorio. Se consideraba que un buen sistema de control interno en sí mismo, podía actuar como un mecanismo de disuasión para la realización de pagos ilegales (Cabezas, 2015).

Durante la década de 1980 se sucedieron una serie de fracasos financieros liderada por quiebras de instituciones afines. De las investigaciones se descubrió que, en casi todos los casos, los auditores no habían emitido ninguna advertencia sobre fraude en sus informes.

Esto llevó a que un grupo de cinco asociaciones de profesionales creara un comité denominado "Comisión Nacional de Informes Financieros Fraudulentos" ("National Commission on Fraudulent Financial Reports"), popularmente conocido como "Comisión Treadway". Dicha Comisión evaluó la erosión que producía el fraude en la integridad de los informes financieros y el rol de los auditores públicos independientes en su detección.

A nivel mundial surgieron otros modelos de control interno, e información financiera, tales como el informe Cadbury producido por el Cadbury Committee en el Reino Unido y el informe Co.Co. elaborado por la junta de criterios de control del Instituto Canadiense de Contadores Matriculados (The Canadian Institute of Chartered Accountants), en Cánada en 1995. No obstante, el marco C.O.S.O. es el de mayor difusión en los países de habla hispana y el que se aplica en Argentina.

\subsubsection{M odelo C.O.S.O. - M arco Integrado de Control Interno}

La Comisión Treadway emitió en 1992 el Informe C.O.S.O, cuyas siglas se relacionan con las organizaciones que lo auspiciaron: "Committee of Sponsoring Organizations". Este documento es el de mayor difusión dentro del habla his- 
pana y es considerado el marco de referencia madre relacionado con el diseño, implementación y desarrollo del control interno y evaluación de su efectividad (PWC \& Instituto de Auditores Internos de España, 2013).

El informe consolida en una sola estructura conceptual diferentes enfoques de Control Interno existentes a nivel mundial. El Marco permite a cualquier tipo de organización, integrar el Control Interno al negocio, de manera que colabore en la obtención de objetivos, como rentabilidad y rendimiento; así como también adaptarse a los cambios del entorno operativo y de negocio, generar información financiera confiable y cumplir con las normas y leyes (PWC \& Instituto de Auditores Internos de España, 2013). El Modelo establece que un sistema de Control Interno efectivo solo ayuda a la organización a lograr sus objetivos, pero no asegura el éxito organizacional.

El informe define al Control Interno de la siguiente manera:

Es un proceso ejecutado por el consejo de directores, la administración y el resto del personal de una entidad, diseñado para proporcionar seguridad razonable con miras a la consecución de objetivos en las siguientes categorías: efectividad y eficiencia de las operaciones; confiabilidad en la información financiera; cumplimiento de las leyes y regulaciones aplicables. (C.O.S.O, 1994, p. 3)

Asimismo, el modelo C.O.S.O determina cinco componentes interrelacionados con las categorías de objetivos: ambiente de control, valoración de riesgos, actividades de control, información y comunicación y supervisión o seguimiento. Los mismos son inherentes a la forma en que la administración dirige el negocio y sirven como criterio para determinar cuándo el sistema es razonable (Casal, 2010).

Las tres categorías de objetivos y los cinco componentes definidos en el modelo se relacionan en tanto los componentes representan aquello que la organización necesita para cumplir con dichos objetivos. Los cinco componentes son interdependientes y su funcionamiento integrado reduce a un nivel aceptable el riesgo de no alcanzar un objetivo, es por ello que no deben ser considerados de manera aislada (PWC \& Instituto de Auditores Internos de España, 2013). 


\subsubsection{M odelo C.O.S.O. E.R.M. (Enterprise Risk Management)}

El trabajo del Comité correspondiente a la Treadway Commission se reanudó en el año 2004 y surgió el modelo C.O.S.O. II sobre Gestión de Riesgos Corporativos (C.O.S.O Enterprise Risk Management), el cual tomando como base el modelo C.O.S.O. original, pone énfasis en los riesgos de la organización. La finalidad de dicho modelo es brindar una estructura que permita identificar, evaluar y gestionar los riesgos (Casal, 2010).

El nuevo enfoque no se emitió con la finalidad de sustituir el marco de control interno del modelo C.O.S.O., sino que lo incorpora como parte de él, lo que permite que las organizaciones puedan mejorar sus prácticas de control interno y encaminarse a desarrollar un proceso más completo de la gestión de riesgo.

El informe C.O.S.O. E.R.M., define a la gestión de riesgos como:

Un proceso efectuado por la junta de directores, la gerencia y otro personal de la entidad, aplicado para el establecimiento de la estrategia y designado para identificar los potenciales acontecimientos que pudieran afectar la entidad, manejar riesgos y proveer una seguridad razonable de alcanzar los objetivos. (C.O.S.O. E.R.M., 2004, p.4)

El informe propone una metodología estándar de gestión de riesgos de manera que la Dirección logre los niveles de desempeño y rentabilidad deseados y prevenga la pérdida innecesaria de recursos o, en su defecto, mantenga las pérdidas en los niveles de tolerancia al riesgo (Velezmoro La Torre, 2010). Dentro de la organización, el enfoque en la gestión de riesgos genera roles y responsabilidades a través de los distintos niveles jerárquicos.

A las tres categorías de objetivos definidos en el informe C.O.S.O (1992), se incorpora el objetivo de Estrategia, el cual se relaciona con las metas de alto nivel, alineadas a la misión y visión del ente. La definición de la estrategia refleja cuál será la elección de la alta dirección en relación a cómo la entidad procurará crear valor para sus grupos de interés (Velezmoro La Torre, 2010).

Los cuatro objetivos mantienen una relación directa con los componentes, los cuales de cinco pasan a ser ocho, a saber: ambiente interno, establecimiento de objetivos, identificación de acontecimientos, valoración del riesgo, respuesta al riesgo, actividades de control, información y comunicación y supervisión o seguimiento (Casal, 2010). Para evaluar la efectividad de la Gestión del Riesgo se debe detectar si todos los componentes están presentes y si funcionan de manera apropiada. 
El modelo contempla un nuevo componente relacionado con el Establecimiento de Objetivos, los que, al ser definidos, le permiten a la Dirección identificar los potenciales eventos que afecten su consecución. Los objetivos estratégicos son la base para los objetivos operativos, de reporte y cumplimiento (Velezmoro La Torre, 2010).

La concepción del riesgo entre ambos reportes es diferente, ya que el primer modelo asimilaba al riesgo como peligro y su comunicación dentro de la organización se realizaba a través de noticias negativas o pérdidas. En contraposición, en el reporte C.O.S.O. E.R.M., el riesgo forma parte de un proceso proactivo tendiente a integrar su gestión a la estrategia de la empresa. A su vez, los grupos de interés ejercen presión para conocer y entender los riesgos que está afrontando la organización (Bertani et al., 2014).

Las principales diferencias relativas a los componentes del modelo C.O.S.O. (1992), se refieren a la Gestión del Riesgo, el cual se abre en tres nuevos componentes. El primero de ellos es la identificación de riesgos que pueden provenir de fuentes externas, tales como factores económicos, de naturaleza y medio ambiente, políticos, culturales, sociales o tecnológicos; o de fuentes internas, por ejemplo, infraestructura, personal, procesos o tecnología. Ambas procedencias pueden influir en la estrategia y en los objetivos. El segundo componente es la valoración del riesgo. Una vez que el acontecimiento es identificado, se procede a considerar cómo los potenciales eventos pueden afectar el logro de los objetivos definidos en el informe. La valoración del riesgo se realiza en dos perspectivas, en función de la Probabilidad de Ocurrencia y de su Impacto. Finalmente, el tercer componente es la respuesta al riesgo. La organización debe evaluar y decidir cuál de las posibles respuestas al riesgo detectado está dispuesta a dar. Para ello, debe considerar la probabilidad y el impacto de ocurrencia del evento, dentro de los límites de tolerancia de la entidad. Las categorías de respuesta son: evitar el riesgo (la acción se aplica a la salida de las actividades que dan origen a los riesgos), reducir o mitigar (disminuyen la probabilidad del riesgo, el impacto o ambos a través de actividades de control), compartir o transferir el riesgo (reducen la probabilidad del impacto del riesgo, transfiriéndolo o compartiendo una parte de él) y aceptación del riesgo (no hay ninguna acción para afectar la probabilidad ni el impacto). 


\subsubsection{M odelo C.O.S.O. III o M odelo C.O.S.O. actualizado}

Debido al proceso de globalización y el avance en las tecnologías de la información, en mayo de 2013 la Treadway Commission modificó el marco integrado generado en 1992. La actualización es conocida como el Modelo C.O.S.O. III, aunque algunos autores lo denominan C.O.S.O. II ya que lo consideran un reajuste del primero sin considerar el C.O.S.O. E.R.M.

La versión de 2013 conserva la definición de Control Interno y sus cinco componentes y mantiene la obligación de considerarlos al momento de evaluar la efectividad del sistema de control interno.

En relación a los objetivos, se sostienen los tres del marco original y se adiciona al objetivo de confiabilidad de la información financiera, la información de tipo no financiera interna y externa y la generación de reportes internos. Esto le brinda sentido a la asociación del modelo C.O.S.O. con buenas prácticas de gestión, ya que el modelo original solo se circunscribía a la confiabilidad de aquellos informes que se relacionaban con la gestión financiera. El Modelo C.O.S.O. III busca ampliar los objetivos hacia aspectos no financieros a partir de indicadores de gestión confiables, oportunos y útiles para la toma de decisiones (Laski, 2013).

Con la finalidad de generar criterios más claros y objetivos sobre el control interno y de facilitar a las organizaciones la implementación del modelo, se formalizaron conceptos a través de diecisiete principios que constituyen nociones fundamentales vinculadas a los cinco componentes del modelo. Es por ello que, para que una organización logre un control interno eficiente se deben aplicar todos ellos.

Los temas relevantes incorporados en la actualización del modelo son los asuntos de fraude y los controles sobre la tecnología de la información. Ambos aspectos han evolucionado durante el período de 1992 a 2013, dada la creciente aparición de casos de fraude organizacional y por la relevancia que adquieren los sistemas informáticos en la gestión de las empresas.

La propuesta del modelo actualizado pone énfasis en considerar el fraude potencial que se puede generar ante la falsedad en los informes, la protección inadecuada de activos y la corrupción en la evaluación de riesgos para el logro de objetivos. Adicionalmente, la organización debe seleccionar y desarrollar las actividades de control generales sobre la tecnología (Laski, 2013). El hecho de utilizar tecnología de información tiene efectos en la estructura del control interno, pero no sobre los objetivos, ni su filosofía. Algunas funciones de los sistemas pueden representar controles cuando estos son diseñados con la finalidad de detectar errores o irregularidades. 


\subsection{M atriz de Riesgos}

La Matriz de Riesgos es una herramienta de control y de gestión que se utiliza con la finalidad de identificar las actividades o procesos más relevantes de la empresa y los niveles y tipos de riesgos inherentes a esas actividades, así como también los factores exógenos y endógenos relacionados.

Asimismo, sintetizan la información relativa a los riesgos que afronta la empresa y colabora en la definición de las estrategias destinadas a mitigar la exposición y los daños potenciales (García Gómez, 1994).

El aporte de información que realiza la Matriz de Riesgos contribuye con el objetivo general de supervivencia de la empresa, ya que permite medir y controlar la exposición de la organización a través de una gestión proactiva del riesgo. Permite también evaluar si la gestión y administración de los riesgos es adecuada, a fin de poder evitar impactos negativos en los resultados y en el logro de los objetivos del ente.

\subsubsection{D esarrollo de la Matriz de Riesgos}

Al iniciar el desarrollo de la Matriz, se debe identificar aquellas actividades y procesos críticos de manera de establecer sus dependencias, potenciales vulnerabilidades y las posibles consecuencias que podrían provocar en toda la organización (Rodríguez López, Piñeiro Sánchez \& Llano Monelos, 2013).

Cada factor identificado debe ser evaluado en relación a su impacto económico y a su influencia en otros procesos. Además, no debe restringirse solo a un análisis histórico ya que es posible que eventos relevantes tengan frecuencias reducidas o no se hayan presentado nunca.

La Matriz de Riesgos se grafica en un plano cartesiano, donde el eje de las $X$ identifica el Impacto que este factor tiene sobre los objetivos estratégicos y el eje de las Y la Probabilidad de Ocurrencia de los factores de riesgo identificados. La combinación de ambas variables define el nivel de riesgo de una operación en particular.

El I mpacto puede ser definido como la calificación de la trascendencia de cada factor de riesgo en relación con el conjunto de vulnerabilidades respecto de la actividad o proceso analizado y de acuerdo con la pérdida máxima que puede producir asumiendo que no existe gestión alguna de este (Rodríguez López et al., 2013). Es imposible definir una escala estándar con parámetros cuantitativos que puedan generalizarse para todas las compañías. 
Al momento de determinar las Probabilidades, se tiene que considerar la frecuencia con la que potencialmente pueden producirse las pérdidas en caso de no existir controles que mitiguen los riesgos.

Del análisis del Impacto y la Probabilidad, se obtiene una calificación inicial para cada riesgo identificado, sin considerar los mecanismos de control interno que pudiesen estar implementados y funcionando de manera adecuada para prevenirlos. Evaluada la existencia del control relacionado, su diseño y funcionamiento, se debe analizar el grado de cobertura que ofrecen dichos mecanismos, que puede ser total, alta, medio, bajo o muy bajo. La cobertura total implica que los controles establecidos eliminan prácticamente la probabilidad de ocurrencia y/o impacto del riesgo; en contraposición, una cobertura muy baja, se da en casos donde no existen controles o no son efectivos, por lo cual no mitigan el riesgo identificado.

Los niveles de riesgos detectados se exponen en la Matriz de Riesgos y se pueden graficar mediante distintos colores. En la Figura $\mathrm{N}^{\circ} 1$, partiendo del ángulo superior derecho y de acuerdo a la gama de colores, el color gris oscuro representa Riesgos Altos y a medida que decrece se encuentran los Riesgos Medios-Altos, luego los Riesgos Medios y finalmente en el tono de gris más claro los Riesgos Bajos. El gráfico tabular sintetiza dicha información a través de colores, de manera de expresar la importancia relativa de cada riesgo y su probabilidad de ocurrencia. Cada organización define la forma de graficar la matriz y los niveles de desglose de riesgos que considera pertinentes.

Una vez que se detectan los riesgos y los controles existentes para mitigarlos, se recomiendan las posibilidades de mejora en el control interno de la empresa, especialmente para aquellos riesgos calificados en las categorías Alto o MedioAlto. Las mejoras a implementar deben ser evaluadas de acuerdo a la relación costo-beneficio, así como también asignar responsables de su implementación.

\section{M etodología}

\subsection{Enfoque de la Investigación}

En función de los objetivos establecidos en la presente investigación, se optó por un enfoque de carácter cualitativo ya que el mismo busca comprender e interpretar el contexto de los acontecimientos en su ambiente natural, tomados tal y como se encuentran, sin que sean reconstruidos o modificados por el investigador (Taylor, 1998). 
Figura No 1. Matriz de Riesgos

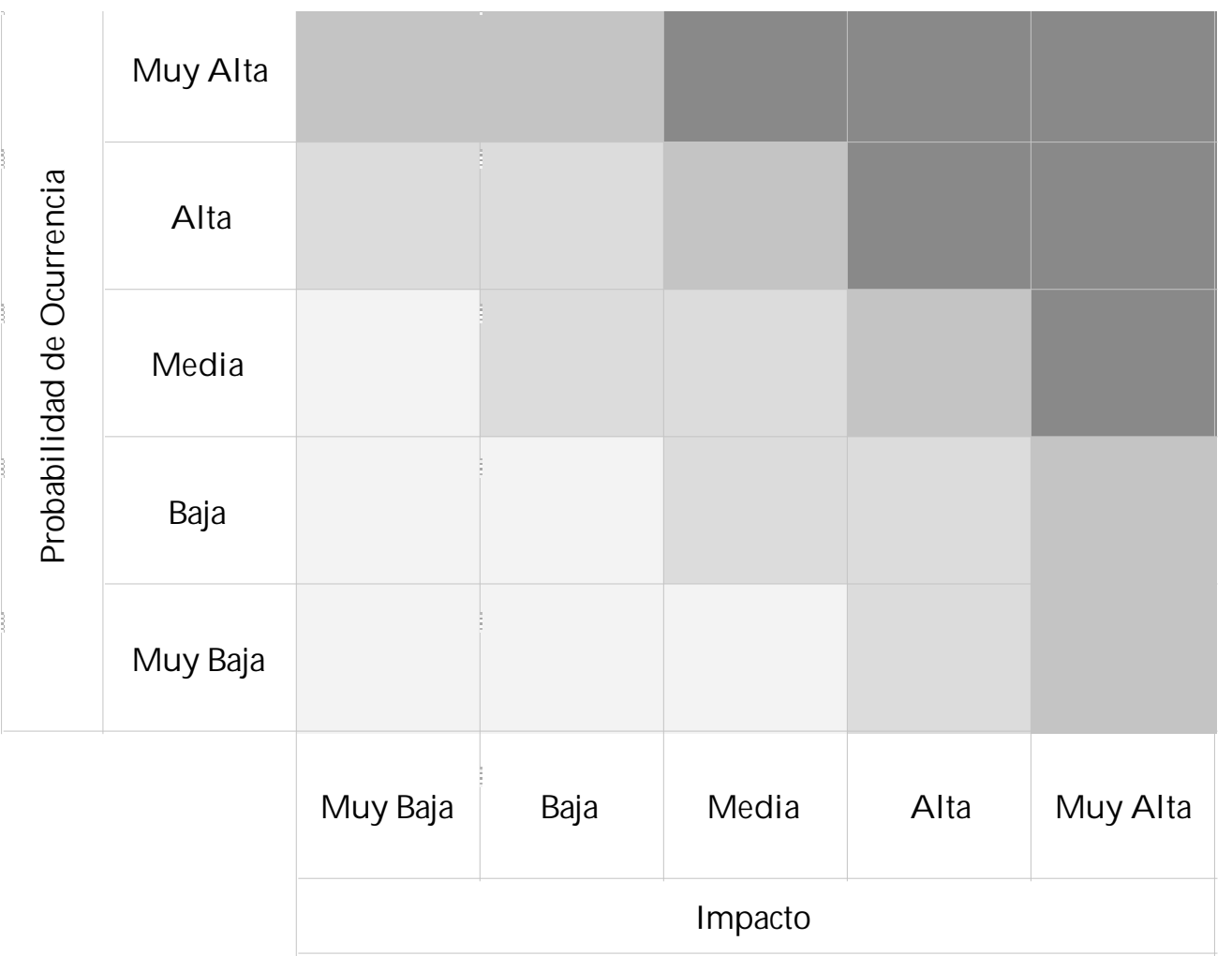

Fuente: Rodriguez Lopez et al., 2013. La gama de grises puede ser representada a través de los siguientes colores: rojo para los Riesgos Altos, color naranja para Riesgos Medios-Altos, color amarillo para Riesgos Medios y color verde para Riesgos Bajos.

La investigación cualitativa no parte de una hipótesis y por lo tanto no pretende demostrar teorías existentes (Hernández Sampieri, Fernández Collado \& Baptista, 2010). Su finalidad es generar teoría a partir del resultado obtenido (Martínez, 2001).

El investigador debe interactuar con los individuos dentro de su contexto social para capturar e interpretar el significado y el conocimiento que tienen de sí mismos y de su realidad, con el objetivo de obtener una aproximación global y naturalista de su ambiente (Martínez, 2001).

En función de lo descripto, se optó por el método de estudio de caso, ya que las características de la investigación se ajustan a lo sostenido por Mertens (2005) quien concibe este procedimiento como una investigación sobre un indi- 
Administración de riesgos: análisis de un proceso de abastecimiento y gestión de insumos críticos

viduo, grupo, organización, comunidad o sociedad, que es visto y analizado como una entidad.

El estudio de caso desarrollado tiene un propósito descriptivo ya que pretende identificar los elementos clave o variables que inciden en el fenómeno a estudiar (Martínez Carazo, 2006), así como también brindar riqueza interpretativa y profundidad a los datos obtenidos (Hernández Sampieri, et al., 2010).

\subsection{Unidad de análisis}

Como se indicó anteriormente, la investigación se llevó a cabo sobre una empresa radicada en el Polo Petroquímico de la ciudad de Bahía Blanca, provincia de Buenos Aires, dedicada a la producción de fertilizantes para la actividad agrícola. La industria es de proceso continuo, lo que significa que la producción es constante las 24 horas del día, durante todo el año. Se reconoció como unidad de análisis al proceso de abastecimiento y gestión de los insumos críticos requeridos para la producción de los productos ofrecidos por la organización. Se eligió este proceso, debido a que un adecuado abastecimiento de insumos críticos resulta de vital importancia en una industria de proceso continuo.

Como insumos clave para el proceso productivo, se reconocieron gas natural, energía eléctrica y agua industrial. La particularidad de dichas materias primas radica en que su abastecimiento constituye un servicio público, por lo cual sus mercados se encuentran regulados por el Estado. Debido a los requerimientos legales y la complejidad de su gestión, requieren que la organización cuente con una estructura interna adecuada que le permita administrar eficientemente su abastecimiento.

Dada la importancia de los insumos críticos para la compañía, sumado a que son recursos escasos y regulados legalmente en la Argentina, resulta de interés identificar y analizar los riesgos a los que está expuesta la organización.

\subsection{Recolección de datos}

En una investigación cualitativa, esta etapa tiene como propósito la obtención de datos de sujetos, comunidades, contextos, variables o situaciones en profundidad (Hernández Sampieri et al., 2010). La recopilación de información fue realizada a través de datos primarios, como entrevistas semiestructuradas, observación participante completa y de datos secundarios, tales como revisión 
bibliográfica y análisis documental de información interna de la organización.

El investigador se desempeña profesionalmente en la organización dentro del área de Planeamiento, Insumos Estratégicos y Control de Gestión desde hace 9 años, lo cual le permite conocer y vivenciar la cultura organizacional. Es por ello que, antes de comenzar con el análisis del proceso clave seleccionado, se procedió a evaluar cuál es la actitud de la entidad hacia el control interno y la gestión de riesgos. Dicha actitud fue juzgada a partir del análisis de contenido de políticas, procedimientos y acciones implementadas por la entidad, de manera de poder conocer previamente cuál será la actitud de gestión de riesgos de los actores relevantes del proceso clave seleccionado.

El área en donde trabaja el investigador desarrolla diversas actividades transversales a toda la organización, lo que le permite tener conocimiento de cuáles son los procesos clave. Las tareas referidas son el presupuesto anual de la compañía, el plan estratégico a cinco años, el tablero de control diario y los reportes de gestión que exponen el desempeño de variables esenciales del negocio y la variación de resultados reales versus planificados.

A partir del año 2015, se creó una Jefatura dentro del área, que involucra el abastecimiento de insumos críticos, presupuesto y control de gestión. El investigador forma parte de ella con el puesto de Analista de Insumos Estratégicos y Control de Gestión, en el que desarrolla las tareas previamente mencionadas y las actividades de certificación y análisis de insumos críticos.

En función de lo anterior, se decidió recopilar información a través de la observación participante completa, ya que el puesto de trabajo que desempeña el investigador le permite interactuar con agentes clave del proceso analizado. La observación facilita la obtención de información sobre el fenómeno a estudiar y permite confirmar los datos obtenidos a partir de entrevistas (Hernández Sampieri et al., 2010).

En primera instancia, se realizó una búsqueda de información dentro de la organización relacionada con la gestión de insumos críticos, es decir, documentos generados y emitidos dentro de la empresa. La información a obtener corresponde a políticas y procedimientos corporativos, descripciones de puestos, organigrama organizacional y toda documentación formal que contribuya a construir un conocimiento acabado de todos los procesos organizacionales relacionados con la unidad de análisis definida.

La empresa cuenta con un sistema informático que compila todos los procedimientos vigentes, por lo que se decidió comenzar la búsqueda allí, a partir de aquellos documentos que estuvieran relacionados con el abastecimiento de insumos críticos. Con la finalidad de obtener mayor conocimiento sobre 
Administración de riesgos: análisis de un proceso de abastecimiento y gestión de insumos críticos

la gestión de la documentación disponible se realizó una entrevista semiestructurada al personal que gestiona y administra dicho sistema. A partir de la búsqueda y del análisis de contenido efectuados, se reconoció que el procedimiento denominado "Logística de materias primas y energías de recepción continua" (Código: PFE-PAR-0004) describía adecuadamente los puestos de trabajo involucrados y actividades relacionadas con insumos críticos.

Del procedimiento, se identificaron los actores intervinientes y se realizaron entrevistas semiestructuradas entre julio de 2017 y mayo de 2018, a nivel de Gerencia y Jefatura. Éstas se llevaron a cabo en forma individual, ya que en dichos niveles existe un conocimiento integral del proceso, además de tener mayor responsabilidad en su cumplimiento. Las preguntas fueron abiertas, efectuadas verbalmente y en el orden previsto, dado que a partir de ellas se podían desarrollar consultas adicionales que brindaran mayor claridad sobre la temática a analizar. Las entrevistas fueron realizadas en el lugar de trabajo, debido a que es el sitio donde existe mayor posibilidad de contacto y facilita la posibilidad de repreguntar en caso de que surgieran dudas.

A partir del análisis de contenido del procedimiento, de las entrevistas realizadas y de la experiencia del investigador en tareas relacionadas con insumos críticos, se identificaron los riesgos, es decir, los eventos con impacto negativo. Dentro del procedimiento, se reconocieron dos subprocesos: abastecimiento de insumos críticos y gestión de insumos críticos. Los riesgos internos de dichos procesos fueron identificados principalmente a partir de actividades que forman parte de las tareas desarrolladas por el investigador dentro del área y por actividades ejecutadas por otros miembros del sector, reconocidos en las entrevistas realizadas.

Para la identificación de los riesgos externos, se realizó un análisis de contenido de la bibliografía especializada relacionada con la legislación que regula los mercados de los insumos críticos de la organización, así como también respecto de la disponibilidad actual y futura de dichos recursos en nuestro país, a partir de una lectura sistemática y objetiva. Para garantizar una correcta comprensión de la información obtenida, se realizó una entrevista no estructurada al consultor externo, experto en el sector, quien ha asesorado tanto a la compañía, como también a la Jefatura y a la Gerencia del área. En relación con el mercado de gas natural, se observó convergencia de opiniones referidas a la mejora en la gestión del suministro durante la época invernal a partir de 2016, debido al aumento en la transparencia de información y en la calidad de la reglamentación. Dicha mejora aun no implica autonomía energética, es decir, que se continúa con la dependencia del factor climático. Con respecto al desarrollo de Vaca Muerta, existió coincidencia de opiniones en relación a la 
continuación de su avance, solo se observaron diferentes posturas en función a su razón. En el caso de la energía eléctrica, los entrevistados manifestaron que las energías renovables continuarán su desarrollo, aunque manifestaron ciertas reservas en relación a aspectos tales como ser una alternativa superadora, en términos económicos, de la producción de gas natural como fuentes de generación eléctrica. Por otro lado, se reconoció la limitación existente en términos de almacenamiento del recurso ya que no se han desarrollado aun tecnologías que lo permitan. Finalmente, en relación con la elevada regulación de los mercados, la misma fue observada a partir de la experiencia del investigador en el desarrollo de su puesto de trabajo, dado que los cambios legislativos tienen impacto directo en las actividades de certificación. Luego de la identificación de los riesgos, se procedió a su evaluación a través de un valor asignado de acuerdo a su impacto y probabilidad de ocurrencia, para luego construir una Matriz de Riesgo que permita a la organización realizar una gestión eficaz en forma integrada a su estrategia corporativa. Finalmente, se propusieron acciones para dar respuesta a la administración de todos los riesgos identificados.

De acuerdo a lo expuesto anteriormente se puede resumir el método de investigación en la tabla 1.

\subsection{O bjetivo de la investigación}

Para el desarrollo de la presente investigación, no se establecieron proposiciones previas a comprobar, ya que la naturaleza de la investigación cualitativa se encuentra orientada al descubrimiento más que a la verificación o refutación.

Tabla 1. Resumen Método de Investigación

\begin{tabular}{cc}
\hline Método de Investigación & Investigación cualitativa \\
\hline Estrategia de investigación & Estudio de caso único \\
\hline Clasificación del estudio de caso & Descriptivo \\
\hline Unidad de análisis & $\begin{array}{c}\text { Proceso de abastecimiento y gestión de los insumos } \\
\text { críticos requeridos para la producción de los productos } \\
\text { ofrecidos por la organización }\end{array}$ \\
\hline Fuente de datos & $\begin{array}{c}\text { Observación participante completa, entrevistas semie- } \\
\text { structuradas, revisión bibliográfica y análisis documental }\end{array}$ \\
\hline
\end{tabular}

Fuente: elaboración propia de acuerdo a Oliveira, Maçada \& Goldoni (2009). 
El objetivo general se refiere a la realización de un diagnóstico de la administración de riesgos vinculados al abastecimiento y gestión de insumos críticos para el proceso de producción de fertilizantes, por un lado y al desarrollo de una matriz de riesgos que permita su gestión, por el otro.

A continuación, se enuncian los objetivos específicos que conforman los hitos a alcanzar para el cumplimiento de la propuesta general:

- Identificar los procesos organizacionales relacionados con el abastecimiento de insumos críticos y su gestión.

- Analizar e identificar los riesgos correspondientes al ambiente interno y externo, asociados a los procesos organizacionales identificados.

- Valorar los riesgos detectados en función de su probabilidad de ocurrencia e impacto.

- Diseñar la matriz de riesgos para analizar la criticidad de los mismos para la organización.

- Diseñar acciones tendientes a gestionar los riesgos más críticos para la organización.

\section{Resultados}

En lo sucesivo, se presentarán los resultados que se obtuvieron de acuerdo a la metodología elegida para la investigación. En la primera subsección, se presentará la orientación de la organización hacia la gestión de riesgo en función de la información relevada durante el estudio de caso. El objetivo es conocer el ambiente de control de la entidad, ya que es la base de todo sistema de control interno y gestión del riesgo, así como también del resto de los componentes del Modelo C.O.S.O. E.R.M.

Luego, se identificarán los riesgos generales a los que se encuentra expuesta la entidad en función de su actividad y, posteriormente, se registrarán los riesgos del proceso clave seleccionado.

A continuación, se valorarán los riesgos para clasificarlos de acuerdo a su impacto y probabilidad de ocurrencia, lo que finalmente nos permitirá construir la Matriz de Riesgos centrada en el proceso clave analizado y proponer acciones de control. 


\subsection{G estión de Riesgos Corporativos}

El Sistema Integral de Gestión (SIG) implementado por la organización se desarrolló en base a las normas emitidas y publicada por la Organización Internacional para la Normalización. Dentro de las mismas, se encuentra la norma ISO 9001, la cual, en el año 2015, fue actualizada a partir de un enfoque basado en riesgos, con la finalidad de que el sistema sea capaz de alcanzar los objetivos propuestos y lograr la mejora continua. Como respuesta a dicho requerimiento, la organización bajo estudio unificó dos procedimientos en uno: Planeamiento Estratégico (PES-GEN-0001 Planeamiento Estratégico) y Riesgo Corporativo (PFE-GEN-0007 Riesgo Corporativo). El nuevo procedimiento se denominó "Planeamiento Estratégico y Riesgo Corporativo (PFE-GEN -0016)".

En dicho documento se detalla el proceso de gestión de riesgos que se ejecuta en la organización a nivel corporativo, lo que permite observar cuál es la actitud que asume la alta dirección y el resto de las gerencias con relación a la importancia del control interno y su incidencia sobre las actividades y resultados.

Se evidencia que el proceso de gestión de riesgos forma parte del establecimiento de la estrategia, ya que el Plan Estratégico de la organización lo contempla. También se observa que es un proceso aplicado a lo largo de la organización dado que la totalidad de las áreas de la compañía nombran referentes que llevan adelante las actividades relacionadas con la gestión de los riesgos detectados.

A partir de la instrumentación del presente procedimiento que involucra a todas las áreas de la entidad, se refuerza el ambiente de desde los niveles más altos de la organización hacia la educación del resto del personal a partir de la conciencia sobre la gestión de riesgos y el control.

Del proceso de evaluación de riesgos corporativos descripto en el procedimiento, se obtiene la Matriz de Riesgos, la cual, por cuestiones de confidencialidad, no será exhibida en este trabajo de investigación.

Es dable destacar la diferencia existente entre la Matriz descripta en los párrafos anteriores y la desarrollada en esta investigación. La primera corresponde a la herramienta de gestión del riesgo establecida por la compañía, la cual ayuda a identificar los diferentes procesos de la organización que suponen un riesgo para la consecución de sus objetivos, por otro lado, la segunda se basa en un proceso clave de la organización, es decir que le brinda a la organización una nueva herramienta de gestión que complementa a la Matriz de Riesgos Corporativa, basada en un proceso crítico para organizaciones industriales. 
En línea con el fortalecimiento del ambiente de control, la organización cuenta con un Código de Ética en el que se detallan las expectativas de la empresa sobre el comportamiento aceptable de sus empleados. Dentro de su contenido, se encuentra el propósito y su importancia para la organización, del comportamiento esperado con respecto a temas tales como la confidencialidad de la información, las relaciones cliente/proveedor y la confidencialidad del contrato, las relaciones con autoridades y funcionarios, los conflictos de interés, la competencia leal e información competitiva, los regalos y favores personales, el lavado de dinero, la conducta personal, el uso de recursos de la empresa (tales como computadoras, telefonía celular, correo electrónico y otros), los recursos disponibles para informar sobre presuntas irregularidades y/o sospechas de mala conducta y las consecuencias respecto del incumplimiento y acciones disciplinarias. Todos los años, los empleados realizan una renovación obligatoria del compromiso a partir de su lectura en su versión multimedia.

\subsection{Identificación de Riesgos}

A continuación, se presentarán los riesgos identificados y su fuente generadora, dada la naturaleza de la actividad de la organización y los riesgos del proceso clave analizado de acuerdo a lo establecido por el modelo C.O.S.O. E.R.M., es decir, la identificación de eventos tanto con impacto negativo (riesgos), como con impacto positivo (oportunidades).

\subsubsection{Riesgos de la O rganización Bajo Estudio}

La organización, por el simple hecho de desarrollar una actividad en un contexto dado, se encuentra expuesta a diversos riesgos. En la tabla 2 se exponen aquellos identificados para la organización y sus principales fuentes generadoras, teniendo en cuenta el caso bajo análisis:

A continuación, por cada riesgo se justifica su identificación:

1) Riesgo Estratégico: dentro de las múltiples fuentes de riesgos estratégicos, para la organización bajo estudio, se reconoce que su característica de industria monoproducto es la principal fuente de vulnerabilidad. La entidad posee una planta industrial con una importante inversión en activos fijos, preparada para la producción de amoníaco y urea granulada. Ante 
Laura Daima

Tabla 2. Riesgos de la organización bajo estudio

\begin{tabular}{|c|c|c|}
\hline Unidad de Análisis & Riesgos Identificado & Fuente \\
\hline \multirow{9}{*}{ Organización } & Estratégicos & Industria monoproducto \\
\hline & Mercado & $\begin{array}{l}\text { Variación precio de referencia de la urea } \\
\text { y precio de materias primas, tipo de } \\
\text { cambio }\end{array}$ \\
\hline & Negocio & Facilidades para importar producto \\
\hline & Legal & $\begin{array}{l}\text { Industria con importante regulación } \\
\text { legal, impositiva, ambiental contable }\end{array}$ \\
\hline & Reputacional & $\begin{array}{l}\text { Impacto ambiental de su actividad en la } \\
\text { comunidad bahiense } \\
\text { Accidentes personales en el desarrollo } \\
\text { de actividad industrial } \\
\text { Incumplimiento de compromisos asumi- } \\
\text { dos con clientes }\end{array}$ \\
\hline & Financiero & $\begin{array}{l}\text { Incumplimiento de obligaciones finan- } \\
\text { cieras o pagos operativos }\end{array}$ \\
\hline & Infraestructura & $\begin{array}{l}\text { Interrupción proceso productivo por } \\
\text { equipos defectuosos }\end{array}$ \\
\hline & Operacional & $\begin{array}{l}\text { Incumplimiento de procedimientos y } \\
\text { procesos internos }\end{array}$ \\
\hline & Tecnológico & Caída del sistema informático SAP ERP \\
\hline
\end{tabular}

Fuente: elaboración propia.

cambios en el mercado o la eventual aparición de productos sustitutos de la urea, la organización tiene acotada la posibilidad de diversificación de producto, al menos en el corto plazo.

2) Riesgo M ercado: la urea granulada es el principal producto de venta de la organización y también es un commodity cuyo precio de referencia lo fija el mercado y se encuentra fuera del poder de gestión de la entidad. La organización se ve expuesta a un alto riesgo representado por los vaivenes de las variaciones en su precio. Adicionalmente, su materia prima principal es el gas natural, el cual se cotiza en dólares, e incorpora un nuevo riesgo representado por variaciones en el tipo de cambio. 
Administración de riesgos: análisis de un proceso de abastecimiento y gestión de insumos críticos

3) Riesgo de N egocio: la organización es la única productora de urea granulada del país, lo que genera, en principio, una ventaja competitiva. Actualmente, existe mayor facilidad para importar productos con respecto a años previos. Esto representa un riesgo para la entidad, ya que sus clientes han capturado una posibilidad que les brinda mayor poder de negociación frente a la organización obligándola a ser aún más competitiva.

4) Riesgo Legal: la industria bajo estudio se encuentra sujeta al cumplimiento de diversas legislaciones. El riesgo al que se expone es la modificación repentina de las mismas, lo que requeriría una rápida adaptación por parte de la entidad a partir de la actualización de procedimientos, políticas y sistemas. Adicionalmente, es necesario que la entidad cuente con asesoría externa para evitar interpretaciones incorrectas o inadecuadas de los nuevos requerimientos legales.

5) Riesgo Reputacional: el desarrollo de la actividad industrial localizada en cercanías a la comunidad convierte a ésta última en un grupo de interés o stakeholder relevante para la entidad. Se requiere que, ante cualquier incidente o accidente, la organización tenga una adecuada política comunicacional, de manera de evitar, en la medida de lo posible, la percepción adversa de dicho stakeholder. Asimismo, se deben considerar los potenciales accidentes personales que puedan surgir en el desarrollo de la actividad, según las características de la industria bajo estudio. Esto puede producir daños a la reputación de la organización. Por otro lado, la planta de producción de urea es el core business de la organización, con lo cual las interrupciones en la producción debidas a una mala performance de la planta o al corte en el suministro de sus insumos críticos pueden generar potenciales incumplimientos de los compromisos asumidos con clientes.

6) Riesgo Financiero: su detección viene asociada al riesgo de mercado, ya que la organización posee obligaciones operativas mensuales, tales como el pago de salarios, gastos fijos, materias primas, proveedores, que deben ser afrontadas en forma independiente de las fluctuaciones en los ingresos de la organización, producto de las variaciones en el precio de referencia de la urea. Asimismo, puede generarse la situación de bajos precios de urea granulada e incremento en los costos, producto de variaciones en el tipo de cambio e inflación.

7) Riesgo de Infraestructura: dado que la industria bajo análisis es de capital intensivo, en línea con el riesgo anterior, se puede reconocer el riesgo de 
infraestructura. El corazón de la organización está dado por su planta de producción, por lo que cualquier defecto en sus equipos tendría un impacto directo en su performance e interrumpiría la producción continua. Esto conlleva a que la organización cuente con planes de mantenimiento preventivo, de manera de realizar un seguimiento del rendimiento de sus equipos y detectar fácilmente cualquier desviación respecto del funcionamiento esperado.

8) Riesgo O peracional: la organización cuenta con procedimientos internos y un sistema informático (SAP ERP) que, a partir de sus diferentes módulos, da soporte a la totalidad de las áreas de la compañía y brinda la posibilidad de trazabilidad en el desarrollo de los procesos corporativos. El riesgo detectado radica en las posibles fallas generadas por seres humanos, sobre cuyo comportamiento se establecen mecanismos de control, como perfiles en sistemas y niveles de autorización, aunque resultan incapaces de cubrir la totalidad de situaciones a las que se encuentran expuestos.

9) Riesgo tecnológico: dado que la organización posee un sistema informático que da soporte a todos sus procesos, existe el riesgo de que se produzca la caída del mismo, lo que produciría alteraciones en el normal desarrollo de sus actividades. Si bien el desarrollo de un sistema acorde a las necesidades de la organización brinda trazabilidad en sus procesos, genera una gran dependencia y la necesidad de contar con un departamento de Sistemas destinado a su mantenimiento.

Además de la identificación de los riesgos organizacionales, se detectaron oportunidades de acuerdo a la visión del Modelo C.O.S.O. E.R.M., el cual amplía la visión del riesgo a eventos negativos o positivos, es decir amenazas u oportunidades. En la tabla 3 se detallan los beneficios detectados, dado que se considera que buscan preservar o crear valor para los stakeholders e, incluso, su ejecución puede actuar como mitigadora de riesgos:

A continuación, se brindarán los argumentos por los cuales se considera que la organización cuenta con dichas oportunidades:

i. Planeamiento Estratégico Corporativo y Sistema Integrado de Gestión: el Planeamiento Estratégico es un proceso que se desarrolla anualmente y posee un procedimiento interno donde se detallan sus diferentes etapas. El área de Planeamiento, Insumos Estratégicos y Control de Gestión, a través del Coordinador de Dirección Estratégica, dependiente del Gerente de Planea- 
Administración de riesgos: análisis de un proceso de abastecimiento y gestión de insumos críticos

Tabla 3. Oportunidades detectadas en la organización bajo estudio

\begin{tabular}{|c|c|c|}
\hline Unidad de Análisis & Oportunidad Identificada & Fuente \\
\hline \multirow{3}{*}{ Organización } & Estratégica & $\begin{array}{l}\text { Planeamiento Estratégico Cor- } \\
\text { porativo y Sistema Integrado de } \\
\text { Gestión }\end{array}$ \\
\hline & Operacional & $\begin{array}{l}\text { Definición de procedimientos, } \\
\text { políticas e instructivos - Herra- } \\
\text { mienta de gestión documental } \\
\text { Definición de un organigrama } \\
\text { organizacional } \\
\text { Sistema informático corporativo } \\
\text { Definición de roles dentro del } \\
\text { sistema informático }\end{array}$ \\
\hline & Reputacional & Código de Ética \\
\hline
\end{tabular}

Fuente: elaboración propia.

miento, Insumos Estratégicos y Control de Gestión; es responsable de llevar adelante el proceso y supervisar su cumplimiento. Para la planificación estratégica, la organización contempla diversas fuentes de información, entre las cuales se encuentran los riesgos identificados en la Matriz de Riesgos corporativa. La estrategia se traduce en proyectos, en los cuales participan todas las áreas de la compañía, definiendo responsables. Adicionalmente, el establecimiento de los objetivos corporativos corresponden a un output del proceso de Planeamiento Estratégico.

El Sistema Integrado de Gestión (SIG) es la herramienta con la que cuenta el Equipo de Dirección para supervisar y gestionar el desempeño de la organización. Dicho sistema se instrumenta a través de procedimientos que guían el accionar de la empresa, en línea con su misión, visión y valores, así como también en relación a con la política integrada de calidad, salud, seguridad, medioambiente y energía, los objetivos e indicadores de gestión y el Código de Conducta Ética. Los procedimientos poseen una actualización periódica y se resguardan en el sistema informático de gestión documental, al que puede acceder todo el personal de la compañía.

ii. D efinición de procedimientos, política e instructiva y herramienta de gestión documental: los procesos organizacionales se encuentran detallados en procedimientos, dentro de la herramienta denominada "PRODOC". Permite mantener en forma ordenada y centralizada todos los procedimientos 
vigentes en la compañía de forma segura ya que los documentos no pueden ser editados. La definición de procedimientos y políticas documentan la descripción de tareas y requerimientos; logran uniformar y controlar las buenas prácticas que llevan a la eficiencia y eficacia y refuerzan la cultura organizacional deseada. Adicionalmente, buscan que las actividades organizacionales se ejecuten de manera de lograr el cumplimiento de los objetivos definidos por la entidad y minimicen la concreción de riesgos.

iii. D efinición de un organigrama organizacional: la organización cuenta con un organigrama formal en donde se detalla su estructura total. La definición del organigrama constituye en forma clara las líneas de mando, es decir establece a quién cada persona debe rendir cuentas y sobre cuáles puede influir. Por otro lado, define las funciones de cada miembro de la organización, evitando la duplicación de tareas o jefaturas múltiples. Este se encuentra instrumentado en un procedimiento.

iv. Sistema informático corporativo: la organización cuenta con un sistema informático corporativo denominado SAP ERP, el cual da soporte a la totalidad de los procesos organizacionales. El sistema fue diseñado de acuerdo a las necesidades de la entidad, considerada como un organismo completo e integrado. El área de Sistemas es la encargada de su actualización y mantenimiento. De esta manera, se logra trazabilidad de las actividades desarrolladas y se evitan trabajos manuales a partir de la automatización de tareas.

v. D efinición de roles dentro del sistema informático: cada empleado, en función de su puesto de trabajo, posee un rol y determinados permisos de acceso dentro del sistema informático. El área de Sistemas gestiona los permisos a partir del formulario de Altas, Bajas y Modificaciones (AMB), el cual es confeccionados por aquellos niveles jerárquicos que poseen personal a cargo. La gestión de permisos resguarda datos de la compañía, tiende a proteger la integridad en la información disponible y asegura que las actividades sean desarrolladas por el personal designado.

vi. Código deÉtica: la organización posee un Código de Ética, que determina los patrones y expectativas de la entidad para con sus trabajadores. El Código busca que tanto empleados como directivos actúen con imparcialidad, es decir, todos los miembros de la organización se ordenan bajo los mismos principios. Los códigos de ética tienden a crear lealtad y colaboración de los empleados hacia la empresa, así como también motivación a partir de la generación de una cultura ética interna. La entidad cuenta con una versión digital del Código, la cual debe ser vista 
obligatoriamente por todos los empleados una vez al año, como refuerzo del compromiso asumido.

\subsubsection{Riesgos del Proceso de Abastecimiento y G estión de Insumos Críticos}

Debido a que el investigador se desarrolla profesionalmente dentro del área que gestiona el abastecimiento de insumos críticos, reconoce que el procedimiento denominado "Logística de materias primas y energías de recepción continua" (Código: PFE-PAR-0004) detalla las tareas relacionadas con el suministro y gestión de insumos críticos y los puestos de trabajo involucrados.

En términos generales, el procedimiento posee un doble propósito, en primer lugar, describir las acciones relativas a la adquisición y gestión de insumos críticos y los puestos de trabajo involucrados en dichas actividades. En segundo lugar, se hace mención a los marcos legales en donde se operan y adquieren las materias primas bajo estudio.

De la lectura del procedimiento, se reconocieron dos subprocesos que abordan la totalidad de actividades involucradas en el abastecimiento de insumos críticos de la organización:

- Proceso de Adquisición de insumos críticos.

- Proceso de Gestión de insumos críticos.

En las siguientes subsecciones se describirán las actividades que involucran a dichos procesos.

\subsubsection{Proceso de Adquisición de Insumos Críticos}

La Gerencia de Planeamiento, Insumos Estratégicos y Control de Gestión (PIE \&CG) es la máxima responsable de la negociación de los contratos de abastecimiento de los insumos críticos para el proceso productivo. Cabe aclarar que en el caso de la energía eléctrica y agua industrial, existe sólo un proveedor disponible: CAMMESA y ABSA, respectivamente. Es por ello que las operaciones se realizan con dichos actores.

En el caso del gas natural, las negociaciones se desarrollan cada año, generalmente a partir del mes de septiembre, en función de las previsiones de 
suministro contempladas en el presupuesto de la compañía para el próximo período. La Jefatura de Insumos Estratégicos, Planeamiento y Control de Gestión, participa junto con la Gerencia en la definición de las estrategias de compra de insumos que resulten más convenientes en relación a volumen y precio. En la sistematización de la negociación se contemplan los objetivos y estrategias establecidas en el proceso de planificación estratégica de la compañía.

Los acuerdos arribados con los proveedores se formalizan a través de contratos y son administrados dentro de la Jefatura de Insumos Estratégicos, Planeamiento y Control de Gestión. Los documentos son incorporados en la intranet utilizada por todos los miembros del área de PIE \&CG, denominada SAP JAM. En dicha herramienta se mantiene actualizada una biblioteca de datos con los contratos celebrados por suministro. Estos se publican en formato PDF, lo cual imposibilita su edición, pero sí se permite su descarga.

Adicionalmente, los contratos se incorporan y formalizan dentro del sistema corporativo ERP SAP (Enterprise Resource Planning - Planificación de recursos empresariales). Dicha tarea es desarrollada por el investigador, en su puesto de Analista de Insumos Estratégicos y Control de Gestión, dependiente de la Jefatura de Insumos Estratégicos, Planeamiento y Control de Gestión.

Para formalizar los contratos dentro del sistema, es necesario que los proveedores se encuentren dados de alta, caso contrario, se solicita su incorporación. Como primer paso, se genera dentro de ERP SAP un documento interno denominado Solicitud de Pedido (SOLP), en el que se realiza una descripción del contrato en forma clara y precisa, indicando la mayor cantidad de información posible de manera de facilitar las tareas posteriores del área de Compras. Esta etapa representa la solicitud de servicio por parte del área para iniciar el proceso de formalización del contrato celebrado dentro del sistema. El monto de la SOLP determina la estrategia de liberación, es decir, aquellos puestos de trabajos de los que se requiere su aprobación. Una vez que la SOLP se encuentra aprobada por todos los niveles requeridos, el Analista de Insumos Estratégicos y Control de Gestión informa vía email al área de Compras para finalizar la incorporación del contrato en el sistema.

El área de Compras genera un documento denominado Contrato Marco $(\mathrm{CM})$, en el que se tienen en cuenta los datos previamente ingresados en la SOLP, dado que debe ser un registro fiel de la solicitud de servicio. Luego de la creación del documento, este debe ser aprobado en primera instancia por el área de Compras y luego respetar la misma estrategia de liberación establecida para la SOLP. 


\subsubsection{Proceso de G estión de insumos críticos}

Del suministro de insumos críticos derivan distintas tareas operativas, las cuales son desarrolladas durante todo el año. De la lectura del procedimiento, se identificaron las siguientes actividades:

- Nominaciones de gas natural.

- Verificación del caudal y presión de agua industrial.

- Certificaciones del suministro de gas natural, energía eléctrica, agua industrial y transporte de gas natural.

- Participación en asociaciones que asesoran e informan a grandes consumidores industriales de gas natural y energía eléctrica.

La primera actividad es desarrollada por el Coordinador de Análisis y Control de Costos e Inversiones, quien forma parte del área de PIE \& CG y reporta en forma directa a la Gerencia. De manera diaria, lleva a cabo el despacho de gas hacia el complejo productivo ya que de acuerdo a los procedimientos establecidos en la ley nacional número 24.076, la empresa es considerada como cargador directo de gas natural. El volumen de gas a nominar surge de la necesidad operativa de materias primas que requiere el proceso productivo, para lo cual el área de Producción, dependiente de la Gerencia de Operaciones Industriales, informa la producción a ejecutar de amoníaco y urea. En el proceso de nominación se respeta el volumen de gas contratado por proveedor.

Dada su actividad de nominación de gas natural, la Transportadora del Gas del Sur S.A. (TGS) le envía mensualmente la documentación relativa a los volúmenes de gas trasladados por los diferentes transportes firmes e interrumpibles (en caso de que se hubiera utilizado), junto con el detalle por proveedor del gas consumido en planta. Dicha información es recibida vía email, los primeros días de cada mes en carácter de valores provisorios y a fin de mes se obtienen los valores definitivos. Habitualmente entre ambas versiones no existen diferencias, pero en caso de existir, se solicita al proveedor la generación de las notas de crédito o débito según corresponda.

En relación a la segunda actividad, el Coordinador de Análisis y Control de Costos e Inversiones es quien verifica en forma diaria que el caudal y presión del agua industrial se encuentre de acuerdo a los valores de contrato.

La tercera actividad es desarrollada por el investigador en el puesto de Analista de Insumos Estratégicos y Control de Gestión. La certificación involucra el control mensual de la correcta facturación de precio y volumen por parte 
de los proveedores de los insumos críticos, de manera que se pueda autorizar el pago del suministro.

La certificación es una actividad operativa que posee gran relevancia en el normal suministro de los insumos estratégicos debido a que demoras en el pago de las facturas pueden dejar expuesta a la organización a interrupciones en el suministro.

En el desarrollo de la actividad se interactúa con otras áreas de la compañía como ser el sector de Cuentas a Pagar, donde se reciben las facturas de los proveedores a través de una página web denominada "Checkpagos" y se remiten vía e-mail al Analista de Insumos Estratégicos y Control de Gestión para su certificación. También el área de Contabilidad indica los porcentajes de imputación a los centros de costos que deben respetarse al momento de la certificación ya que los insumos forman parte del costo de producción de la compañía y poseen un rol relevante en la determinación de resultados económicos.

En el caso de la factura de energía eléctrica, CAMMESA envía una notificación por correo electrónico cuando un nuevo documento es emitido. El Analista de Insumos Estratégicos y Control de Gestión descarga de la página web dicha documentación y la remite al área de Cuentas a Pagar para que tome conocimiento de la factura y fecha de vencimiento.

Continuando con la descripción de las tareas involucradas en la certificación, se encuentra el control del volumen facturado por el proveedor. En el caso de gas natural, dicho control se realiza con la información enviada por TGS, en la que se detalla la cantidad de gas consumido por proveedor. Este documento es enviado vía e-mail por el Coordinador de Análisis y Control de Costos e Inversiones al Analista de Insumos Estratégicos y Control de Gestión. La verificación de precios se realiza en función de las tarifas que figuran en los contratos celebrados con cada empresa proveedora.

Para la energía eléctrica, el control de volumen y precio es realizado por un consultor externo, a quien se le envía el documento para que chequee la correcta facturación por parte de CAMMESA. Luego de su revisión, se recibe un correo electrónico confirmando la veracidad de los valores liquidados por el proveedor.

En el caso del agua industrial, el control de volumen se realiza a través de un email que se recibe mensualmente desde el área de Procesos, el que se indica cuál fue el consumo de agua cruda de la planta, el cual debe coincidir con el facturado por el proveedor. En relación al precio, se encuentra fijado por contrato, por lo que debe respetar el acuerdo celebrado.

Luego de los controles, la certificación del servicio se realiza en el sistema 
ERP SAP. El volumen facturado se ingresa de forma manual y se multiplica automáticamente por el precio pactado que previamente se ingresó en el Contrato Marco (CM), el cual representa la formalización del contrato celebrado en el sistema corporativo descripto en el subproceso anterior.

El sistema brinda un número que codifica cada certificación, denominado Hoja de Entrada (HE). Dicho código es enviado por correo electrónico al Gerente de PIE \& CG para que apruebe en el sistema la certificación del servicio.

En el caso de la facturación del transporte de gas por parte de TGS, las tarifas son fijadas por ley. En el proceso de certificación se controla que los cargos se mantengan fijos y de acuerdo a lo establecido.

$\mathrm{Al}$ igual que en el caso de la SOLP y el CM, para la aprobación de las HE existen valores predeterminados que determinan los niveles jerárquicos que pueden liberar dichos documentos.

Finalmente, se encuentra la participación como socio de la Jefatura de Insumos Estratégicos, Planeamiento y Control de Gestión en las asociaciones de grandes consumidores, tales como la Asociación de Consumidores Industriales de Gas de la República Argentina (ACIGRA) y la Asociación Grandes Usuarios de Energía Eléctrica de la República Argentina (AGUEERA). Dicha actividad implica la participación en reuniones con la finalidad de mantenerse actualizado ante cambios regulatorios en los mercados, obtener asesoramiento técnico, así como también lograr contacto directo con las autoridades regulatorias.

Como resumen de los procesos presentados y a modo de clarificar las diferentes etapas que los componen, las figuras 2 y 3 buscan sintetizar gráficamente las actividades descriptas: 


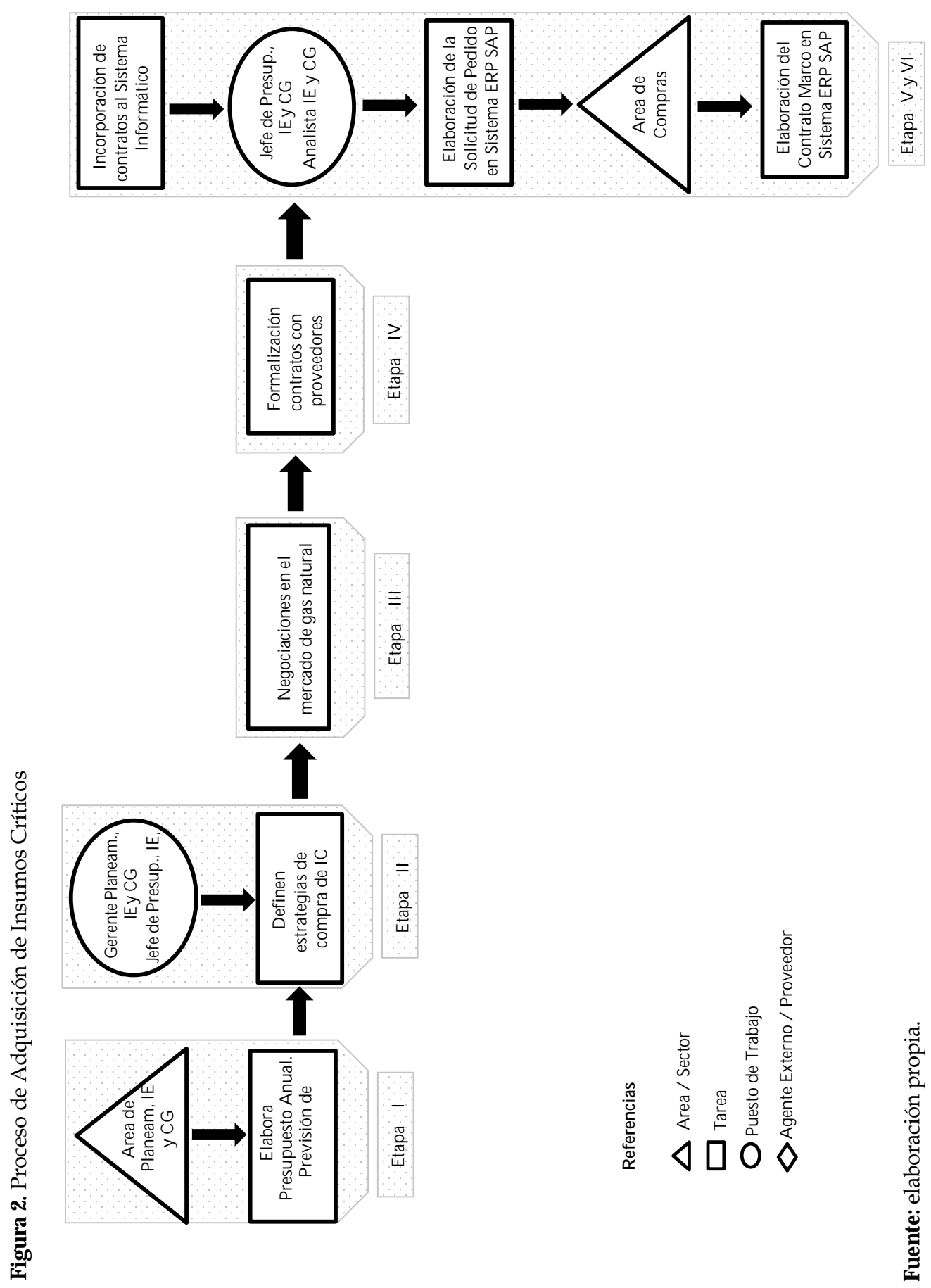


Administración de riesgos: análisis de un proceso de abastecimiento y gestión de insumos críticos

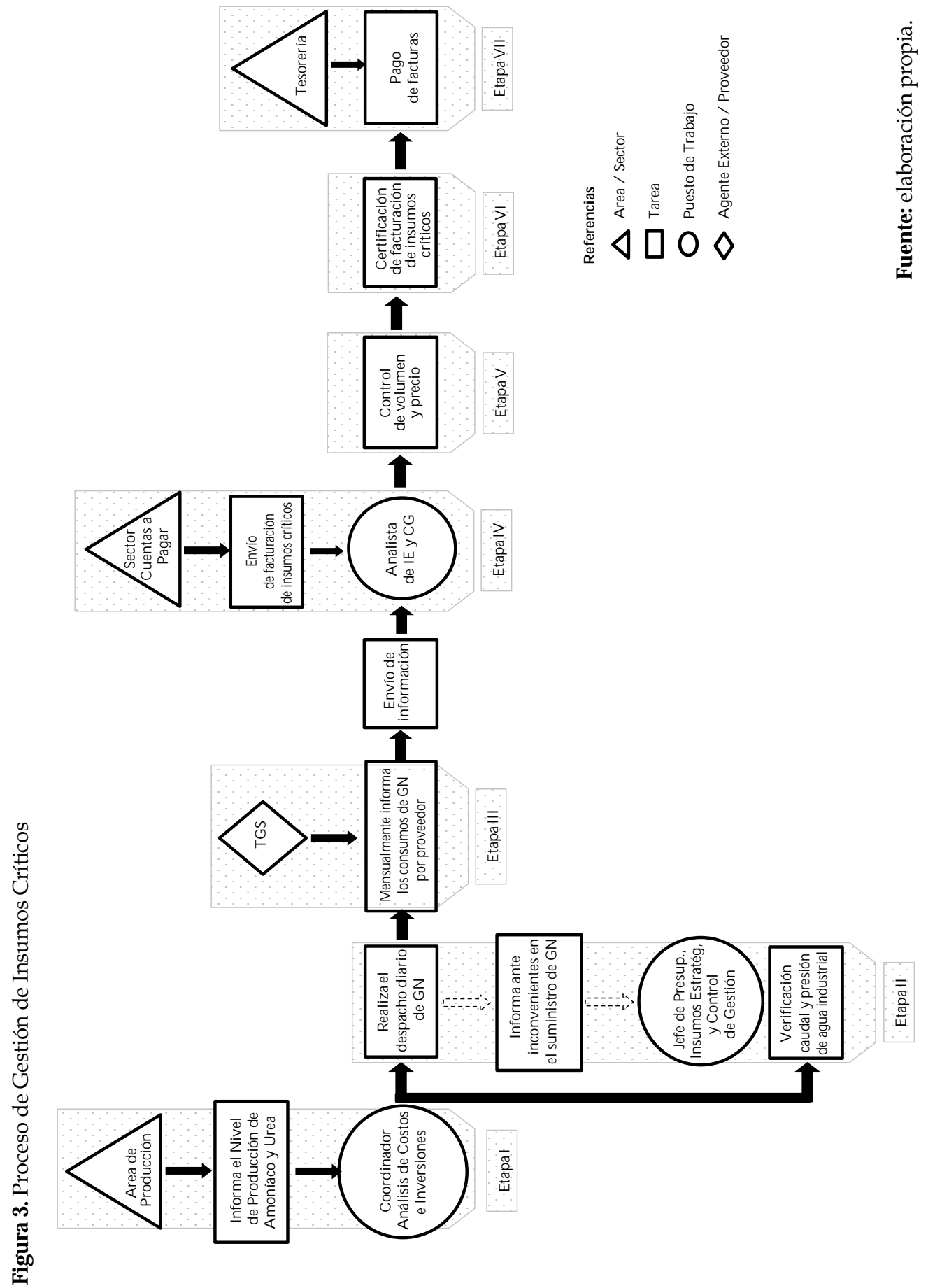

Escritos Contables y de Administración 


\subsubsection{Identificación riesgos del proceso}

De acuerdo a lo expuesto anteriormente, se detectaron dos subprocesos internos de la compañía que hacen a la gestión integral del abastecimiento de materias primas: los procesos de adquisición y gestión de insumos críticos.

Cabe destacar que cada año, a partir de septiembre hasta diciembre, la ejecución de ambos subprocesos se solapa, ya que se comienza con las negociaciones de insumos para el próximo año y al mismo tiempo, se gestionan los insumos correspondientes al año en curso. En función de ello y con el objetivo de facilitar y dar un orden a la detección de los riesgos del proceso de abastecimiento de insumos críticos, se considerará primero la ejecución de su adquisición para luego llevar a cabo su gestión. De esta manera, se observa al proceso interno de abastecimiento de insumos críticos como un todo, con un orden de ejecución determinado y compuesto por las etapas que componen a cada uno de los subprocesos.

Es dable destacar que en el proceso de adquisición de insumos críticos para las etapas II a IV relacionadas con la definición de estrategias de compra de los insumos, la ejecución de las negociaciones y la formalización de los contratos no serán reconocidos riesgos, ya que se considera que son aspectos confidenciales de la organización.

De acuerdo a los gráficos expuestos anteriormente, el subproceso de abastecimiento de insumos críticos se compone de seis etapas y el subproceso de gestión de insumos críticos, de siete. De las diferentes etapas del proceso integral de abastecimiento de insumos críticos, se detectaron 20 riesgos, los cuales se encuentran expuestos en la tabla 4.

A continuación, se identificaron los riesgos externos relacionados con los mercados de insumos críticos, ya que, si bien se encuentran fuera del ámbito de gestión de la organización, tienen influencia en el proceso de abastecimiento de insumos críticos de la compañía. Para ello, se trataron por separado los mercados de gas natural, energía eléctrica y agua industrial dadas las particularidades de cada insumo.

En el mercado de gas natural se identificaron cinco riesgos que pueden afectar a la organización bajo estudio, en el mercado de energía eléctrica se detectaron cuatro riesgos y dos en el mercado de agua industrial. En la tabla 5 se detallan los mismos. 
Tabla 4. Identificación de riesgos del proceso de abastecimiento y gestión de insumos críticos

\begin{tabular}{|c|c|c|c|}
\hline Etapa & Factor del Riesgo & $\begin{array}{l}\text { Código del } \\
\text { Riesgo }\end{array}$ & Riesgo \\
\hline
\end{tabular}

\section{SUBPROCESO: ADQUISICIÓN DE IN SUMOS CRÍTICOS}

\begin{tabular}{|c|c|c|c|c|}
\hline $\mathbf{I}$ & $\begin{array}{l}\text { Proceso presupuestar- } \\
\text { io: previsión de insu- } \\
\text { mos críticos para el } \\
\text { año próximo }\end{array}$ & $\begin{array}{l}\text { Desarrollo del final del proceso } \\
\text { presupuestario en forma concom- } \\
\text { itante con las negociaciones con } \\
\text { proveedores. }\end{array}$ & 1 & $\begin{array}{l}\text { Asignación de recursos humanos del área } \\
\text { en ambos procesos (superposición de } \\
\text { tareas). }\end{array}$ \\
\hline II & $\begin{array}{l}\text { Definición de las } \\
\text { estrategias de compras } \\
\text { de los insumos críticos }\end{array}$ & & & \\
\hline III & $\begin{array}{l}\text { Ejecución de negoci- } \\
\text { aciones con provee- } \\
\text { dores }\end{array}$ & & & \\
\hline IV & $\begin{array}{l}\text { Formalización de los } \\
\text { contratos con prov- } \\
\text { eedores }\end{array}$ & & & \\
\hline \multirow{2}{*}{$\mathbf{v}$} & \multirow{2}{*}{$\begin{array}{l}\text { Incorporación con- } \\
\text { tratos al sistema } \\
\text { informático: SAP } \\
\text { ERP. Generación de la } \\
\text { SOLP y aprobación de } \\
\text { los niveles jerárquicos } \\
\text { requeridos }\end{array}$} & $\begin{array}{l}\text { Demora en el perfeccionamiento de } \\
\text { contratos al iniciar el año (poste- } \\
\text { rior al 31/1), retrasa el proceso de } \\
\text { formalización de los contratos en el } \\
\text { sistema informático corporativo. }\end{array}$ & 2 & $\begin{array}{l}\text { No certificación de facturas emitidas por } \\
\text { proveedores por consumos de enero. } \\
\text { Imposibilidad de librar el pago (demoras } \\
\text { en la formalización de contratos). }\end{array}$ \\
\hline & & $\begin{array}{l}\text { Demoras en la estrategia de lib- } \\
\text { eración de SOLP por los niveles } \\
\text { jerárquicos requeridos posterior } \\
\text { al } 31 / 1 \text {. }\end{array}$ & 3 & $\begin{array}{l}\text { No certificación de facturas emitidas por } \\
\text { proveedores por consumos de enero. } \\
\text { Imposibilidad de librar el pago (demoras } \\
\text { en la aprobación por niveles jerárquicos } \\
\text { requeridos). }\end{array}$ \\
\hline \multirow{3}{*}{ VI } & \multirow{3}{*}{$\begin{array}{l}\text { Generación del Con- } \\
\text { trato Marco por el área } \\
\text { de Compras y apro- } \\
\text { bación por los niveles } \\
\text { jerárquicos requeridos }\end{array}$} & $\begin{array}{l}\text { Actividad desarrollada fuera del } \\
\text { área que administra los insumos } \\
\text { críticos. }\end{array}$ & 4 & $\begin{array}{l}\text { Retrasos en la generación del CM debido a } \\
\text { otras actividades del sector. Imposibilidad } \\
\text { de llevar a cabo la certificación y librar } \\
\text { el pago. }\end{array}$ \\
\hline & & $\begin{array}{l}\text { Riesgo operativo: errores en la } \\
\text { confección de los CM. }\end{array}$ & 5 & $\begin{array}{l}\text { Los datos incorporados en el CM no } \\
\text { respetan lo establecido en la SOLP. }\end{array}$ \\
\hline & & $\begin{array}{l}\text { Demoras en la estrategia de lib- } \\
\text { eración del } \mathrm{CM} \text { por los niveles } \\
\text { jerárquicos requeridos posterior } \\
\text { al } 31 / 1 .\end{array}$ & 6 & $\begin{array}{l}\text { No certificación de facturas emitidas por } \\
\text { proveedores por consumos de enero. } \\
\text { Imposibilidad de librar el pago. }\end{array}$ \\
\hline \multicolumn{5}{|c|}{ SUBPROCESO: ADMINISTRACIÓN DE INSUMOS CRÍTICOS } \\
\hline $\mathbf{I}$ & $\begin{array}{l}\text { Área de producción } \\
\text { informa el nivel de } \\
\text { producción para } \\
\text { estimar la necesidad } \\
\text { de insumos }\end{array}$ & $\begin{array}{l}\text { Es una actividad relevante que se } \\
\text { realiza diariamente y se informa vía } \\
\text { e-mail o telefónicamente, no queda } \\
\text { registro en el sistema informático } \\
\text { corporativo. }\end{array}$ & 7 & $\begin{array}{l}\text { Pérdida de los registros y trazabilidad de } \\
\text { la información. }\end{array}$ \\
\hline \multirow{2}{*}{ II } & $\begin{array}{l}\text { Nominación diaria de } \\
\text { gas natural }\end{array}$ & $\begin{array}{l}\text { Actividad desarrollada diariamente } \\
\text { y por una sola persona, requiere un } \\
\text { back up dentro del área. }\end{array}$ & 8 & $\begin{array}{l}\text { Asignación de recursos humanos del área } \\
\text { para desarrollar la nominación de gas } \\
\text { natural, superposición de tareas. }\end{array}$ \\
\hline & $\begin{array}{l}\text { Verificación de caudal } \\
\text { y presión de agua } \\
\text { industrial }\end{array}$ & $\begin{array}{l}\text { Actividad desarrollada diariamente } \\
\text { y por una sola persona, requiere un } \\
\text { back up dentro del área. }\end{array}$ & 9 & $\begin{array}{l}\text { Asignación de recursos humanos del área } \\
\text { para desarrollar la nominación de gas } \\
\text { natural, superposición de tareas. }\end{array}$ \\
\hline III & $\begin{array}{l}\text { TGS envía vía email } \\
\text { los consumos men- } \\
\text { suales por proveedor }\end{array}$ & $\begin{array}{l}\text { La información no es recibida en } \\
\text { forma directa por la persona que } \\
\text { lleva a cabo la certificación de los } \\
\text { insumos. }\end{array}$ & 10 & $\begin{array}{l}\text { Olvido de reenvío del mail correspondi- } \\
\text { ente al Analista de Insumos Estratégicos y } \\
\text { Control de Gestión. }\end{array}$ \\
\hline
\end{tabular}




\section{Laura Daima}

\begin{tabular}{|c|c|c|c|}
\hline Etapa & Factor del Riesgo & $\begin{array}{l}\text { Código del } \\
\text { Riesgo }\end{array}$ & Riesgo \\
\hline
\end{tabular}

\section{SUBPROCESO: ADQUISICIÓN DE INSUMOS CRÍTICOS}

\begin{tabular}{|c|c|c|c|c|}
\hline \multirow{2}{*}{ IV } & \multirow{2}{*}{$\begin{array}{l}\text { Sector Cuentas a } \\
\text { pagar envía facturas al } \\
\text { Analista de Insumos } \\
\text { Estratégicos para } \\
\text { certificación }\end{array}$} & $\begin{array}{l}\text { El sector que certifica no recibe en } \\
\text { forma directa las facturas de los } \\
\text { proveedores. }\end{array}$ & 11 & $\begin{array}{l}\text { Riesgo operativo: olvido de reenvío de la } \\
\text { facturación. }\end{array}$ \\
\hline & & $\begin{array}{l}\text { No se lleva a cabo una revisión } \\
\text { diaria de las facturas recibidas. }\end{array}$ & 12 & $\begin{array}{l}\text { Retrasos en el reenvío de facturas a cer- } \\
\text { tificar. }\end{array}$ \\
\hline \multirow{6}{*}{$\mathbf{V}$} & $\begin{array}{l}\text { Certificación de Insu- } \\
\text { mos Críticos: Control } \\
\text { volumen facturado de } \\
\text { gas natural }\end{array}$ & $\begin{array}{l}\text { Ante diferencias entre el volumen } \\
\text { informado por TGS y el facturado, } \\
\text { se contacta vía mail al proveedor } \\
\text { para conciliar la diferencia. }\end{array}$ & 13 & $\begin{array}{l}\text { Demora de respuesta por parte del prov- } \\
\text { eedor, retrasa el proceso de certificación. }\end{array}$ \\
\hline & $\begin{array}{l}\text { Control precio factura- } \\
\text { do de gas natural }\end{array}$ & $\begin{array}{l}\text { El sistema informático sólo permite } \\
\text { dos decimales, existen tarifas con } \\
\text { tres decimales. }\end{array}$ & 14 & $\begin{array}{l}\text { Certificación de importes que difieren de } \\
\text { los facturados. }\end{array}$ \\
\hline & $\begin{array}{l}\text { Control facturación } \\
\text { transporte de gas } \\
\text { natural }\end{array}$ & $\begin{array}{l}\text { No se han detectado factores de } \\
\text { riesgos. }\end{array}$ & $\mathrm{N} / \mathrm{A}$ & $\mathrm{N} / \mathrm{A}$ \\
\hline & $\begin{array}{l}\text { Envío facturación a } \\
\text { consultor externo para } \\
\text { control facturación de } \\
\text { energía eléctrica }\end{array}$ & $\begin{array}{l}\text { El sector que certifica no realiza en } \\
\text { forma autónoma el control de la fac- } \\
\text { turación de energía eléctrica, existe } \\
\text { dependencia del consultor externo. }\end{array}$ & 15 & $\begin{array}{l}\text { Retiro del consultor que convalida la } \\
\text { facturación de energía eléctrica. }\end{array}$ \\
\hline & $\begin{array}{l}\text { Control precio de agua } \\
\text { industrial }\end{array}$ & $\begin{array}{l}\text { Error en la base de facturación de } \\
\text { los días calendario del mes. }\end{array}$ & 16 & $\begin{array}{l}\text { Facturación incorrecta, mayor cargo } \\
\text { liquidado. }\end{array}$ \\
\hline & $\begin{array}{l}\text { Control volumen de } \\
\text { agua industrial }\end{array}$ & $\begin{array}{l}\text { El sector de Procesos envía la } \\
\text { información vía e-mail, no queda } \\
\text { registro en el sistema informático } \\
\text { corporativo. }\end{array}$ & 17 & $\begin{array}{l}\text { Pérdida de los registros y trazabilidad de } \\
\text { la información. }\end{array}$ \\
\hline \multirow{2}{*}{ VI } & \multirow{2}{*}{$\begin{array}{l}\text { Ejecución de la certifi- } \\
\text { cación en el sistema } \\
\text { SAP ERP }\end{array}$} & $\begin{array}{l}\text { Actividad desarrollada fuera de la } \\
\text { fecha de vencimiento producto de } \\
\text { demoras en las etapas anteriores. }\end{array}$ & 18 & $\begin{array}{l}\text { Certificación posterior al vencimiento de la } \\
\text { factura, potencial generación de intereses } \\
\text { por mora. }\end{array}$ \\
\hline & & $\begin{array}{l}\text { Incorrecta imputación a los centros } \\
\text { de costos indicados por el área } \\
\text { Contable. }\end{array}$ & 19 & $\begin{array}{l}\text { Generación de distorsiones en el costo de } \\
\text { producción de los productos originados en } \\
\text { la compañía. }\end{array}$ \\
\hline VII & Pago de facturas & $\begin{array}{l}\text { Pago de facturas fuera de término. } \\
\text { Actividad ejecutada por sectores } \\
\text { ajenos al cual realiza la adminis- } \\
\text { tración de los insumos críticos. }\end{array}$ & 20 & $\begin{array}{l}\text { Pago de facturas fuera de término, per- } \\
\text { juicio financiero para la organización y } \\
\text { pérdida de reputación de la empresa en } \\
\text { dichos mercados como buen pagador. }\end{array}$ \\
\hline
\end{tabular}


Administración de riesgos: análisis de un proceso de abastecimiento y gestión de insumos críticos

tabla 5. Identificación riesgos externos mercado de insumos críticos

\begin{tabular}{|c|c|c|c|}
\hline Mercado & Factor del Riesgo & $\begin{array}{l}\text { Código } \\
\text { del } \\
\text { Riesgo }\end{array}$ & Riesgo \\
\hline \multirow{5}{*}{ Gas Natural } & $\begin{array}{l}\text { Interrupción del suministro en } \\
\text { época invernal }\end{array}$ & 21 & $\begin{array}{l}\text { Interrupción de la producción conti- } \\
\text { nua por cortes en el suministro de gas } \\
\text { natural. }\end{array}$ \\
\hline & Demanda domiciliaria & 22 & $\begin{array}{l}\text { No modificación de conducta de consu- } \\
\text { mo por parte de demanda domiciliaria } \\
\text { (demanda inelástica) }\end{array}$ \\
\hline & Desarrollo de Vaca Muerta & 23 & $\begin{array}{l}\text { No se lleven a cabo las inversiones } \\
\text { necesarias para lograr el proceso de } \\
\text { extracción. }\end{array}$ \\
\hline & $\begin{array}{l}\text { Mercado altamente regulado } \\
\text { (riesgo regulatorio) }\end{array}$ & 24 & $\begin{array}{l}\text { Modificaciones intempestivas de la legis- } \\
\text { lación que puedan afectar al negocio. }\end{array}$ \\
\hline & $\begin{array}{l}\text { Discontinuidad de políticas } \\
\text { que beneficien al mercado por } \\
\text { recambio de gobierno (riesgo } \\
\text { político) }\end{array}$ & 25 & $\begin{array}{l}\text { Políticas de incentivo a la producción de } \\
\text { gas natural con un horizonte de corto } \\
\text { plazo. }\end{array}$ \\
\hline \multirow{4}{*}{$\begin{array}{l}\text { Energía } \\
\text { Eléctrica }\end{array}$} & $\begin{array}{l}\text { Matriz energética argentina no } \\
\text { diversificada }\end{array}$ & 26 & $\begin{array}{l}\text { Alta dependencia del gas natural } \\
\text { (recurso escaso) para generar energía } \\
\text { eléctrica, posibilidad de interrupción del } \\
\text { suministro }\end{array}$ \\
\hline & $\begin{array}{l}\text { Nueva legislación de energía } \\
\text { renovables }\end{array}$ & 27 & $\begin{array}{l}\text { Energías renovables es un mercado en } \\
\text { desarrollo, pocos oferentes. }\end{array}$ \\
\hline & $\begin{array}{l}\text { Mercado altamente regulado } \\
\text { (riesgo regulatorio) }\end{array}$ & 28 & $\begin{array}{l}\text { Modificaciones intempestivas de la legis- } \\
\text { lación que puedan afectar al negocio. }\end{array}$ \\
\hline & $\begin{array}{l}\text { Discontinuidad de políticas } \\
\text { que beneficien al mercado por } \\
\text { recambio de gobierno (riesgo } \\
\text { político) }\end{array}$ & 29 & $\begin{array}{l}\text { Políticas de incentivo a la generación } \\
\text { de energía eléctrica con un horizonte de } \\
\text { corto plazo. }\end{array}$ \\
\hline \multirow[b]{2}{*}{ Agua Industrial } & $\begin{array}{l}\text { Alta dependencia de cues- } \\
\text { tiones climáticas (potenciales } \\
\text { sequías) }\end{array}$ & 30 & $\begin{array}{l}\text { Posible reducción/interrupción del } \\
\text { suministro. }\end{array}$ \\
\hline & $\begin{array}{l}\text { Utilización del Dique Paso Pie- } \\
\text { dras como Parque Provincial } \\
\text { con fines de recreación, pesca } \\
\text { deportiva. }\end{array}$ & 31 & Reducción en la calidad del agua. \\
\hline
\end{tabular}

Fuente: elaboración propia. 


\subsection{Valoración de Riesgos}

En la presente sección se evaluarán los riesgos detectados de acuerdo a su impacto y probabilidad de ocurrencia, lo que determinará su ubicación dentro de la Matriz de Riesgos. La evaluación de riesgos permite conocer cuáles son aquellos que deben ser gestionados dada su significatividad, de manera que la organización pueda tomar decisiones en cuanto a la asignación de recursos para su mitigación.

Los riesgos identificados fueron valorados de acuerdo al conocimiento del negocio y del proceso clave analizado. Se asignó un valor a cada riesgo determinado por el producto de dos variables: Probabilidad de 0 currencia (representada por las veces que el riesgo se ha manifestado o puede manifestarse en el proceso) e Impacto (representada por la magnitud de las consecuencias en caso de su materialización).

Para el desarrollo de la escala de dichas variables, se consideró la técnica cualitativa de medición ordinal, a partir de la cual los riesgos son calificados de acuerdo a su grado de importancia. Para ambas se utilizaron las mismas etiquetas de tipo Alta, Media o Baja, representadas, en el caso de la Probabilidad de Ocurrencia, en una escala incrementada en forma geométrica $(1,3,5)$ y en el caso del Impacto, una escala de 1 a 3 . En la tabla 6 se representan las Escalas de Probabilidad de Ocurrencia e Impacto:

Tabla 6. Escala de Probabilidad de ocurrencia e Impacto

\begin{tabular}{|c|c|c|c|}
\hline \multicolumn{2}{|c|}{ Probabilidad de Ocurrencia } & \multicolumn{2}{|c|}{ Impacto } \\
\hline Baja & 1 & Bajo & 1 \\
\hline Media & 3 & Medio & 2 \\
\hline Alta & 5 & Alto & 3 \\
\hline
\end{tabular}

Fuente: elaboración propia.

De acuerdo a la escala definida, la probabilidad de ocurrencia es Baja (1) cuando los eventos son poco frecuentes, es decir una periodicidad de dos veces al año; será Media (3) cuando los eventos suceden con cierta frecuencia, entre tres y cinco veces al año y Alta (5) cuando la ocurrencia del evento es habitual, esto es, superior a cinco veces al año. En el caso del Impacto, será Bajo (1) cuando el impacto no es grave para la organización, Medio (2) cuando los eventos comienzan a tener significatividad para la organización y Alto (3) cuando las consecuencias son significativas para la entidad. 
Administración de riesgos: análisis de un proceso de abastecimiento y gestión de insumos críticos

La evaluación de cada riesgo fue realizada en forma individual, considerando la información obtenida en entrevistas, la experiencia del investigador en el desarrollo de sus funciones y el conocimiento del negocio y de los mercados de insumos críticos. En la tabla 7 se expone la valoración de los riesgos detectados, a los cuales se les asignó un valor que surge del producto entre su Probabilidad de Ocurrencia e Impacto de acuerdo a las escalas definidas previamente. A modo de ejemplo, en el Anexo I, se presenta la justificación de la Probabilidad de ocurrencia e Impacto para cada nivel de riesgo identificado, ya sea interno o externo. Cabe aclarar que a nivel externo, no se identificaron riesgos aceptables, por lo que se exponen dos riesgos de nivel moderado.

Tabla 7. Calificación de los riesgos

\begin{tabular}{|c|c|c|c|c|}
\hline $\begin{array}{l}\text { Código del } \\
\text { Riesgo }\end{array}$ & Descripción & $\begin{array}{l}\text { Probabilidad de } \\
\text { Ocurrencia }\end{array}$ & Impacto & $\begin{array}{l}\text { Calificación } \\
\text { del Riesgo }\end{array}$ \\
\hline 21 & $\begin{array}{l}\text { Interrupción de la producción continua por } \\
\text { cortes en el suministro de gas natural. }\end{array}$ & 5 & 3 & 15 \\
\hline 24 & $\begin{array}{l}\text { Modificaciones intempestivas de la legislación } \\
\text { que puedan afectar al negocio. }\end{array}$ & 5 & 3 & 15 \\
\hline 27 & Pocos oferentes de energías renovables. & 5 & 3 & 15 \\
\hline 28 & $\begin{array}{l}\text { Modificaciones intempestivas de la legislación } \\
\text { que puedan afectar al negocio. }\end{array}$ & 5 & 3 & 15 \\
\hline 12 & Retrasos en el reenvío de facturas a certificar. & 5 & 2 & 10 \\
\hline 4 & $\begin{array}{l}\text { Retrasos en la generación del CM debido a otras } \\
\text { actividades del sector. Imposibilidad de llevar a } \\
\text { cabo la certificación y librar el pago. }\end{array}$ & 3 & 3 & 9 \\
\hline 13 & $\begin{array}{l}\text { Demora de respuesta por parte del proveedor, } \\
\text { retrasa el proceso de certificación. }\end{array}$ & 3 & 3 & 9 \\
\hline 22 & $\begin{array}{l}\text { No modificación de conducta de consumo por } \\
\text { parte de la demanda domiciliaria (demanda in- } \\
\text { elástica) }\end{array}$ & 3 & 3 & 9 \\
\hline 25 & $\begin{array}{l}\text { Políticas de incentivo a la producción de gas nat- } \\
\text { ural con un horizonte de corto plazo. }\end{array}$ & 3 & 3 & 9 \\
\hline 26 & $\begin{array}{l}\text { Modificaciones en la matriz energética nacional: } \\
\text { reducción de la dependencia del gas natural para } \\
\text { generar energía eléctrica. }\end{array}$ & 3 & 3 & 9 \\
\hline 29 & $\begin{array}{l}\text { Políticas de incentivo a la generación de energía } \\
\text { eléctrica con un horizonte de corto plazo. }\end{array}$ & 3 & 3 & 9 \\
\hline 30 & $\begin{array}{l}\text { Posible reducción/interrupción del suministro } \\
\text { por crisis hídrica. }\end{array}$ & 3 & 3 & 9 \\
\hline 31 & $\begin{array}{l}\text { Reducción en la calidad del agua debido al de- } \\
\text { sarrollo de actividades recreativas o pesca de- } \\
\text { portiva en el dique. }\end{array}$ & 3 & 3 & 9 \\
\hline 11 & $\begin{array}{l}\text { Riesgo operativo: olvido de reenvío de la fac- } \\
\text { turación. }\end{array}$ & 3 & 2 & 6 \\
\hline
\end{tabular}




\section{Laura Daima}

\begin{tabular}{|c|c|c|c|c|}
\hline $\begin{array}{l}\text { Código del } \\
\text { Riesgo }\end{array}$ & Descripción & $\begin{array}{l}\text { Probabilidad de } \\
\text { Ocurrencia }\end{array}$ & Impacto & $\begin{array}{l}\text { Calificación } \\
\text { del Riesgo }\end{array}$ \\
\hline 15 & $\begin{array}{l}\text { Retiro del consultor que convalida la facturación } \\
\text { de energía eléctrica. }\end{array}$ & 3 & 2 & 6 \\
\hline 23 & No desarrollo de Vaca Muerta. & 3 & 2 & 6 \\
\hline 8 & $\begin{array}{l}\text { Asignación de recursos humanos del área para } \\
\text { desarrollar la nominación de gas natural (super- } \\
\text { posición de tareas). }\end{array}$ & 5 & 1 & 5 \\
\hline 9 & $\begin{array}{l}\text { Asignación de RRHH del área para la veri- } \\
\text { ficación de caudal y presión de agua (super- } \\
\text { posición de tareas). }\end{array}$ & 5 & 1 & 5 \\
\hline 1 & $\begin{array}{l}\text { Asignación de recursos humanos del área en am- } \\
\text { bos procesos (superposición de tareas). }\end{array}$ & 5 & 1 & 5 \\
\hline 2 & $\begin{array}{l}\text { No certificación de facturas emitidas por prov- } \\
\text { eedores por consumos de enero. Imposibilidad } \\
\text { de librar el pago (demoras formalización de con- } \\
\text { tratos). }\end{array}$ & 1 & 3 & 3 \\
\hline 3 & $\begin{array}{l}\text { No certificación de facturas emitidas por prov- } \\
\text { eedores por consumos de enero. Imposibilidad } \\
\text { de librar el pago (demoras en la aprobación por } \\
\text { niveles jerárquicos requeridos). }\end{array}$ & 1 & 3 & 3 \\
\hline 5 & $\begin{array}{l}\text { Los datos incorporados en el CM no respetan lo } \\
\text { establecido en la SOLP. }\end{array}$ & 3 & 1 & 3 \\
\hline 6 & $\begin{array}{l}\text { No certificación de facturas emitidas por prov- } \\
\text { eedores por consumos de enero. Imposibilidad } \\
\text { de librar el pago. }\end{array}$ & 1 & 3 & 3 \\
\hline 7 & $\begin{array}{l}\text { Pérdida de registro diario del volumen de gas } \\
\text { requerido para la producción. }\end{array}$ & 3 & 1 & 3 \\
\hline 18 & $\begin{array}{l}\text { Certificación posterior al vencimiento de la fac- } \\
\text { tura, potencial generación de intereses por mora. }\end{array}$ & 1 & 3 & 3 \\
\hline 19 & $\begin{array}{l}\text { Generación de distorsiones en el costo de pro- } \\
\text { ducción de los productos originados en la com- } \\
\text { pañía. }\end{array}$ & 1 & 3 & 3 \\
\hline 17 & $\begin{array}{l}\text { Pérdida de los registros mensuales del volumen } \\
\text { consumido de agua. }\end{array}$ & 3 & 1 & 3 \\
\hline 20 & $\begin{array}{l}\text { Pago de facturas fuera de término, perjuicio fi- } \\
\text { nanciero para la organización y pérdida de rep- } \\
\text { utación de la empresa en dichos mercados como } \\
\text { buen pagador. }\end{array}$ & 1 & 3 & 3 \\
\hline 10 & $\begin{array}{l}\text { Olvido de reenvío del mail correspondiente al } \\
\text { Analista de Insumos Estratégicos y Control de } \\
\text { Gestión. }\end{array}$ & 1 & 1 & 1 \\
\hline 14 & $\begin{array}{l}\text { Certificación de importes que difieren de los fac- } \\
\text { turados. }\end{array}$ & 1 & 1 & 1 \\
\hline 16 & $\begin{array}{l}\text { Facturación incorrecta de acuerdo a los días cal- } \\
\text { endarios del mes. }\end{array}$ & 1 & 1 & 1 \\
\hline
\end{tabular}

Fuente: elaboración propia. 


\subsection{M atriz de Riesgos}

Una vez que los riesgos fueron calificados, se procedió a su evaluación, con la finalidad de determinar su ubicación dentro de la Matriz de Riesgos.

La Matriz de Riesgos es una herramienta de control y de gestión que permite presentar de manera gráfica la probabilidad de ocurrencia y el impacto de los factores de riesgo previamente identificados. A partir de su construcción se facilita la determinación de prioridades para la toma de decisiones en relación a los riesgos que merecen ser tratados.

Los niveles de riesgos fueron definidos de acuerdo a un rango numérico en función de las calificaciones de los mencionados en la Figura $N^{\circ} 10$, de forma tal que pueden ser considerados Aceptables, Moderados o Inaceptables, de acuerdo a lo expuesto en la tabla 8:

Tabla 8. Nivel de Riesgo

\begin{tabular}{ccccl}
\hline Nivel de Riesgo & Desde & Hasta & Curso de Acción Requerido \\
\hline Aceptable & $\mathbf{1}$ & $\mathbf{5}$ & Riesgo con impacto bajo, no se requiere acciones adicionales. \\
\hline Moderado & $\mathbf{6}$ & $\mathbf{9}$ & $\begin{array}{l}\text { Se requieren acciones de corrección a mediano plazo para monitorear } \\
\text { el riesgo. }\end{array}$ \\
\hline Inaceptable & $\mathbf{1 0}$ & $\mathbf{1 5}$ & Se establecen planes para tratar el riesgo. \\
\hline
\end{tabular}

Fuente: elaboración propia.

En la figura 4 se encuentra la Matriz de Riesgos, en donde fueron ubicados los 31 riesgos identificados. Los números situados en cada cuadrante hacen referencia al Nivel de Riesgo expuesto en la Figura $\mathrm{N}^{\circ}$ 9, de manera de poder asociarlo al riesgo al cual corresponden:

Los riesgos que se encuentran en la zona de color gris más claro son considerados Aceptables, es decir, que no representan riesgos, pero deben ser monitoreados de manera que se mantengan dentro de dicha asignación. Los riesgos en la zona de color gris intermedio son calificados como Moderados, de modo que deben ser gestionados, ya que, de no tratarse, pueden afectar a la organización. Finalmente, los riesgos que se encuentran en la zona de color gris más oscuro son considerados Inaceptables, por lo cual se deben ejercer acciones tendientes a su mitigación para que no afecte significativamente a la organización. 


\section{Laura Daima}

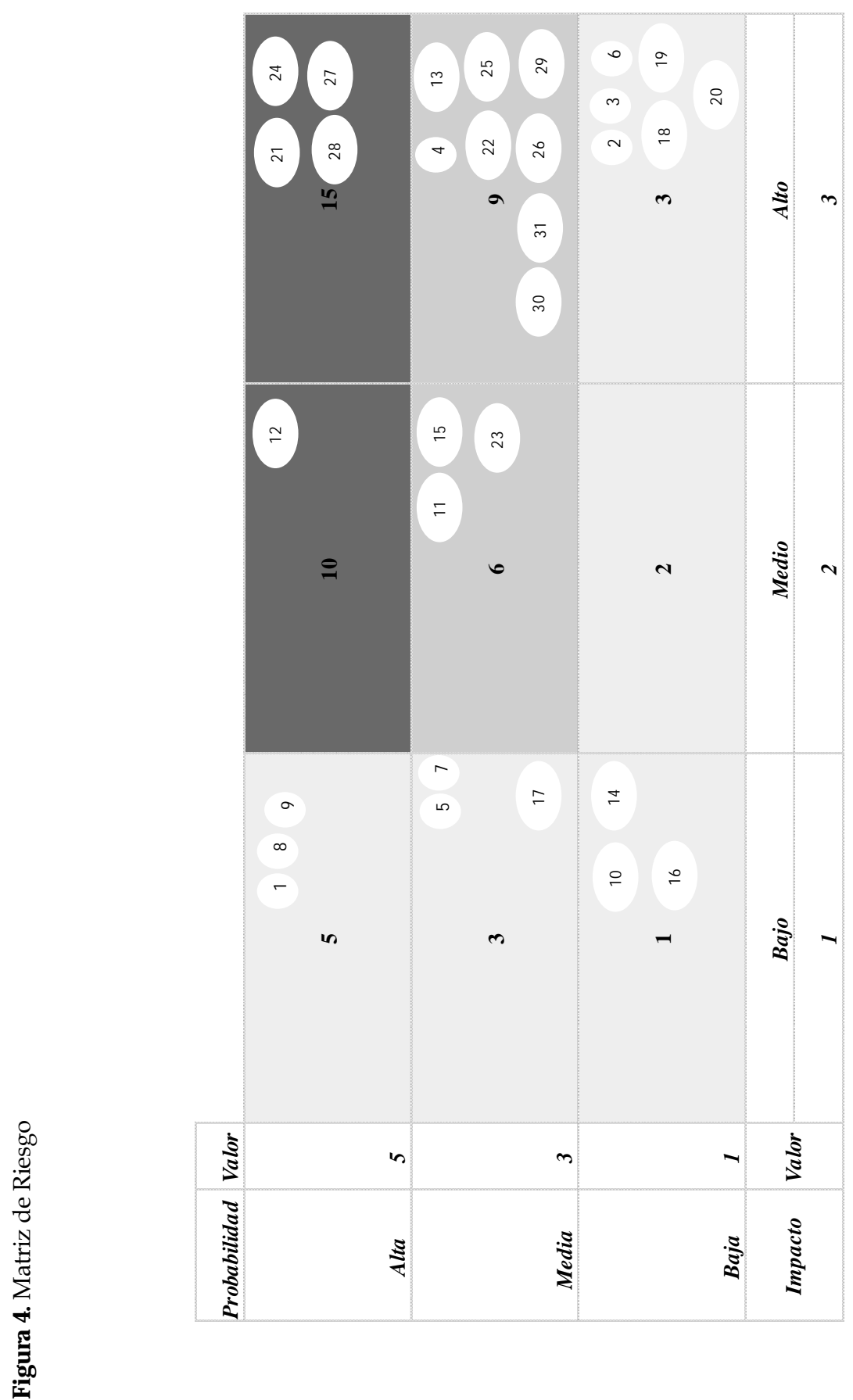


De los 31 riesgos detectados, $20(65 \%)$ corresponden a riesgos internos del proceso organizacional de abastecimiento de insumos críticos y $11(35 \%)$ a riesgos externos correspondientes a los mercados de insumos críticos.

Los riesgos internos advertidos en el proceso de abastecimiento de insumos críticos se componen, en relación con su nivel de riesgo, de la siguiente manera: el 75\% (15 riesgos) es considerado Aceptable, 20\% (4 riesgos) Moderados y el $5 \%$ restante (1 riesgo) se ubica en la zona de Inaceptables.

Los riesgos externos de los mercados de insumos críticos son analizados en conjunto y se disponen de este modo: $64 \%$ (7 riesgos) se percibe como Moderado y el 36\% restante (4 riesgos) se ubica en la zona de riesgos Inaceptables.

A modo de resumen en la tabla 9 se tabulan los datos expresados anteriormente:

Tabla 9. Resumen riesgos detectados

\begin{tabular}{|c|c|c|c|c|c|}
\hline Riesgos & Cantidad & $\%$ & Nivel de Riesgo & Cantidad & $\%$ \\
\hline \multirow{3}{*}{ Internos } & \multirow{3}{*}{20} & \multirow{3}{*}{$65 \%$} & Aceptable & 15 & $75 \%$ \\
\hline & & & Moderado & 4 & $20 \%$ \\
\hline & & & Inaceptable & 1 & $5 \%$ \\
\hline \multirow{3}{*}{ Externos } & \multirow{3}{*}{11} & \multirow{3}{*}{$35 \%$} & Aceptable & 0 & $0 \%$ \\
\hline & & & Moderado & 7 & $64 \%$ \\
\hline & & & Inaceptable & 4 & $36 \%$ \\
\hline TOTAL & 31 & $100 \%$ & TOTAL & 31 & \\
\hline
\end{tabular}

Fuente: elaboración propia.

Si se considera la totalidad de riesgos detectados, tanto internos como externos, se obtiene un total de 31 riesgos, de los cuales el 48\% (15 riesgos) es considerados como Aceptable; 36\% (11 riesgos) corresponde a riesgos Moderados y el 16\% restante (cinco riesgos) se relaciona con riesgos Inaceptables.

Aquellos evaluados como Aceptables, abarcan cinco cuadrantes de la Matriz, principalmente el correspondiente a la probabilidad de ocurrencia baja e impacto alto, con un total de 6 riesgos de los 15 considerados como Aceptables. Tres poseen impacto y probabilidad de ocurrencia baja y de los 6 restantes, la mitad posee probabilidad de ocurrencia media e impacto bajo, mientras que el resto una probabilidad de ocurrencia alta e impacto bajo.

De los riesgos valorados como Moderados, 8 de los 11 corresponden a aquellos cuya ponderación es nueve (probabilidad media e impacto alto) y los 3 res- 
tantes poseen una ponderación de seis (probabilidad de ocurrencia e impacto medio). Finalmente, se hallaron 5 riesgos valorados como Inaceptables, 4 de ellos con una ponderación de quince, es decir probabilidad de ocurrencia e impacto alto. El restante, cuenta con una ponderación de diez (probabilidad de ocurrencia alta e impacto medio).

\subsection{Respuesta al Riesgo}

En la presente sección se exponen las acciones propuestas tendientes a dar respuesta a los riesgos identificados. A modo de ejemplo, en el Anexo II se listan las acciones pensadas para los riesgos presentados en el Anexo I.

De los 20 riesgos internos detectados, sólo el número 12 denominado "Retrasos en el reenvío de facturas a certificar", es considerado como Inaceptable. En dicho caso la acción propuesta tiende a reducir el riesgo a partir de la solicitud a los contactos comerciales de los proveedores de insumos críticos, del envío de una notificación vía email al Analista de Insumos Estratégicos y Control de Gestión cuando expiden las facturas a la organización. De esta manera, en caso de que la documentación aun no haya sido enviada por el sector de Cuenta a Pagar se puede realizar el reclamo correspondiente y obtener la facturación para realizar la certificación en tiempo y forma y evitar retrasos.

En el caso del riesgo número 14, denominado "Certificación de importes que difieren de los facturados", la acción propuesta sugiere aceptarlo, puesto que el mismo se origina en una configuración definida para el software corporativo. De todas formas, el mayor riesgo de certificar montos diferentes a los facturados sería el pago de un importe incorrecto, situación poco probable, ya que el proceso de pago es desarrollado por el sector de Cuentas a Pagar, quien contabiliza la factura en el sistema por el monto expresado y, por ende, el desembolso se realiza de acuerdo al mismo.

Para los siguientes 7 riesgos, a saber, $\mathrm{N}^{\circ} 1$ "A signación de R RHH del área en ambos procesos (superposición de tareas)."; N 4 "Retrasos en la generación del CM a tiempo debido a otras actividades del sector."; $N^{\circ} 13$ "D emora de respuesta por parte del proveedor, retrasa el proceso de certificación."; $\mathrm{N}^{\circ} 15$ "Retiro del consultor que convalida la facturación de energía el éctrica." ; N 16 "Facturación incorrecta de acuerdo a los días calendarios del mes." ; $\mathrm{N}^{\circ} 18$ "Certificación posterior al vencimiento de la factura, potencial generación de intereses por mora." y $\mathrm{N}^{\circ} 20$ "Pago de facturas de insumos críticos fuera de término.", se proponen acciones tendientes a reducir los riesgos, ya que en la mayoría de ellos intervienen otras áreas de la organi- 
Administración de riesgos: análisis de un proceso de abastecimiento y gestión de insumos críticos

zación, las cuales deben adoptar las medidas de control propuestas aunque se continúa expuesto al riesgo operativo derivado de la potencial falla humana de la ejecución de las actividades de control. En el caso del riesgo $\mathrm{N}^{\circ} 1$, interno del área responsable del abastecimiento de insumos críticos, se propone el desarrollo de un cronograma que contemple los hitos claves del proceso presupuestario y de adquisición de insumos críticos, de manera de reducir la superposición de tareas en momentos significativos para ambas actividades. Finalmente, en el caso del riesgo $\mathrm{N}^{\circ} 15$, también se proponen acciones a desarrollar dentro del área de Planeamiento, Insumos Estratégicos y Control de Gestión, tendientes a morigerar el impacto del posible retiro intempestivo del consultor, a partir de la capacitación del Analista de Insumos Estratégicos y Control de Gestión, de manera que pueda desarrollar el control de la facturación en forma autónoma. Por otro lado, se sugiere el desarrollo de búsquedas en el mercado para contar con otras opciones ante un eventual retiro del consultor.

Para los 11 riesgos restantes, las acciones propuestas buscan evitarlo a partir de mejoras a implementar en el sistema informático corporativo SAP o en los sistemas de correo interno de la compañía, optimizando el uso de las herramientas disponibles dentro de la organización. Adicionalmente, para los riesgos $\mathrm{N}^{\circ} 8$ "A signación de RRH H del área para desarrollar la nominación de gas natural." y No 9 "A signación de RRHH del área para desarrollar la actividad de verificación del caudal y presión de agua.", se propone el desarrollo de un back up interno dentro del área de Planeamiento, Insumos Estratégicos y Control de Gestión de manera de poder salvaguardar potenciales licencias o períodos vacacionales del puesto de trabajo que desarrolla dicha actividad.

En relación a los riesgos externos, se debe considerar que en todos los casos la organización no tiene gran poder de gestión sobre ellos, ya que provienen del contexto. Por tal motivo, se propone a la organización mantener su participación en asociaciones tales como ACIGRA y AGUEERA, ya que le permitiría conocer los cambios en la legislación con la mayor anticipación posible, lograr asesoramiento técnico respecto al entendimiento integral de los cambios a implementarse y generar los potenciales cursos de acción destinados a la posible amortiguación del cambio.

En el caso de gas natural, es relevante mencionar que la organización forma parte del Comité de Emergencia del ENARGAS, lo cual le permite anticiparse en el conocimiento de posibles cortes o restricciones y planificar de la mejor manera posible el escenario de producción y los compromisos asumidos con clientes.

En términos generales, se puede afirmar que, si bien la organización no tiene un gran poder de gestión sobre riesgos externos, ha implementado acciones 
destinadas a estar presente en los ámbitos donde se obtiene información relevante sobre los insumos críticos para la entidad.

\section{Conclusiones}

El objetivo general de la investigación fue la realización de un diagnóstico de la administración de riesgos vinculados al suministro y gestión de insumos críticos para el proceso de producción de fertilizantes y el desarrollo de una Matriz de Riesgos que permita su gestión. De acuerdo a tal fin, se identificaron los procesos organizacionales relacionados con el abastecimiento y gestión de insumos críticos, de manera de poder analizar e identificar los riesgos correspondientes al ambiente interno y externo, asociados a dicho proceso. A continuación, los riesgos fueron valorados de acuerdo a su probabilidad de ocurrencia e impacto, con la finalidad de poder confeccionar la Matriz de Riesgos y analizar la criticidad de los mismos para la organización.

Del estudio realizado, se detectaron 31 riesgos, de los cuales el 48\% (15 riesgos) son considerados como Aceptables; el 36\% (11 riesgos) corresponde a riesgos Moderados y el 16\% restante (5 riesgos) fue valorado como Inaceptable. Del total, el 65\% corresponde a riesgos internos y el 35\%, a externos, lo cual, es positivo para la organización, ya que la mayoría de los riesgos pueden ser gestionados internamente.

Como resumen de las vulnerabilidades detectadas como internas, en su mayoría corresponden a riesgos operativos, para los cuales se propusieron acciones de control que tiendan a la optimización de las herramientas corporativas disponibles, tales como mejoras en el sistema informático corporativo o en el sistema de mailing.

En el caso de los riesgos externos, la organización no posee gestión directa sobre los mismos, de todas formas, se observa que la entidad reconoce su existencia y busca formar parte de asociaciones que le permitan obtener información de relevancia para poder gestionar los cambios derivados principalmente de los mercados de insumos críticos.

El método de investigación elegido resultó adecuado, ya que el proceso de abastecimiento y gestión de insumos críticos pudo ser analizado como una entidad, dentro de su contexto real, lo cual permitió identificar las variables que afectan al proceso examinado. Se considera que fue clave el hecho de que el investigador formara parte de la organización, ya que la unidad de análisis constituye parte de su puesto de trabajo y rutina, lo que le brinda gran cono- 
Administración de riesgos: análisis de un proceso de abastecimiento y gestión de insumos críticos

cimiento al respecto y sobre sus implicancias para la organización.

El trabajo de investigación le proporciona a la entidad una herramienta que permite la optimización de su proceso de abastecimiento de insumos críticos a partir de acciones de mejora, tanto internas del área que gestiona los insumos, así como también de aquellas áreas con las cuales interactúa en el proceso y los proveedores. Adicionalmente, es relevante mencionar que el análisis realizado permite complementar la Matriz de Riesgo corporativa que elabora la entidad de acuerdo al procedimiento mencionado en la sección "4.1.Gestión de Riesgos Corporativos". Ambos procesos se desarrollan de manera equivalente desde el punto de vista conceptual, lo que le facilitará a los niveles directivos de la organización, la interpretación de los resultados de la investigación, puesto que la mecánica de trabajo les resultará familiar.

Los riesgos detectados en el proceso son esencialmente de tipo operativo, no se identifcó ninguno de gran relevancia que pueda generar un perjuicio negativo a la organización desde el punto de vista financiero o económico. Se puede concluir que el nivel de riesgo detectado en el proceso es producto de la definición e implementación de sistemas de control interno, tales como políticas corporativas determinadas en los procedimientos que dan soporte a los procesos organizacionales, así como también la gestión documental a partir de un sistema informático con actualización periódica (Prodoc), la implementación de un organigrama corporativo, el Sistema Integrado de Gestión, el Código de Ética, el sistema informático corporativo que da soporte a la totalidad de operaciones de la organización, la definición de perfiles dentro del sistema informático tendientes al resguardo de la documentación, entre otras.

Si bien el investigador conocía la existencia de los sistemas de control interno establecidos por la organización, el presente estudio permitió comprobar la efectividad de su diseño y funcionamiento, lo que brindó trazabilidad y transparencia a todo el proceso analizado. En función de los riesgos identificados para la unidad de análisis, se pudo comprobar que los sistemas de control establecidos cumplen con sus objetivos esenciales de resguardo de los recursos de la empresa para evitar pérdidas por fraude o negligencia y la detección de desvíos que puedan afectar al cumplimiento de sus objetivos.

Cabe mencionar que, a pesar de las herramientas establecidas por la entidad tendientes al cumplimiento de sus objetivos, las organizaciones en general quedan expuestas a riesgos operativos con origen humano, como posibles fallas en los procesos asociadas a negligencias o errores derivados de factores de comportamiento, los cuales son imprevisibles a pesar de los sistemas de control interno implementado. 
Dado que el investigador forma parte de la organización, se pudo realizar un aporte al desarrollo de su capital humano a partir del estudio realizado, ya que se han intensificado los conocimientos y competencias que se consolidan en mejoras de las actividades laborales.

Con la finalidad de testear si las acciones de control propuestas logran dar respuesta a los riesgos detectados, se sugiere volver a aplicar el modelo al proceso analizado en el presente trabajo. Sería conveniente que el estudio sea realizado con posterioridad a la finalización del período que involucra el proceso descripto, de manera de tener una visión integral y poder evaluar si se han producido cambios en el nivel de riesgos detectados.

También se propone ejecutar el modelo en otros procesos críticos de la organización, tales como procesos comerciales relativos a la gestión de ventas o procesos financieros correspondientes a la gestión de cobranzas y pagos. Como punto de partida, dichos procesos poseen un procedimiento interno, el cual puede ser testeado de la misma manera que fue analizado el proceso de abastecimiento y gestión de insumos críticos.

Como limitación de la investigación, se reconoce que fue desarrollada sobre un estudio de caso único, el cual posee validez para describir la realidad social de la organización analizada, pero carece de la posibilidad lógica de transferir las conclusiones a otros casos no examinados. A pesar de ello, se observa que se han comprobado los beneficios de los sistemas de control interno y gestión de riesgos establecidos en la organización, lo cual sí es aplicable para cualquier otra organización.

Finalmente, cabe mencionar los beneficios que conlleva el desarrollo de la investigación como actividad de vinculación entre la comunidad académica y la industria local. Es un circuito que se retroalimenta, ya que se produce una confluencia de intereses que genera una mayor producción académica y promueve la creación de innovación, con un impacto práctico en la industria a partir de mejoras a sus procesos.

\section{Referencias bibliográficas}

Association of Insurance and Risk Managers, Alarm \& Institute of Risk Management (2010). A structured approach to Enterprise Risk M anagement. Recuperado de: https:/ / www.theirm.org/media/886062/ISO3100_doc.pdf.

Bertani E., Polesello M., Sánchez Mendoza M. y Troila J. (2014). COSO I Y coso II, U na propuesta integrada. Facultad de Ciencias Económicas, Uni- 
versidad Nacional de Cuyo, Mendoza, Argentina. Recuperado de: http:/ / bdigital.uncu.edu.ar/objetos_digitales/6694/bertanipolesellosancheztroila-tesisfce.pdf

Cabezas, V. (2015). “La ley FCPA, ¿un caso de jurisdicción universal?". Law Review, 2. Recuperado de: http:/ / www.usfq.edu.ec/publicaciones/lawreview/Documents/edicion003/la w_review_005.pdf.

Casal, A. (2010). Gobierno Corporativo. D irección, administración y control de organizaciones en forma ética y responsable. Buenos Aires; ERREPAR.

Castro, A., Saavedra García, M.L. y Camarena Adame, M.E. (2015). Hacia una comprensión de los conceptos de emprendedores y empresario. Suma N egocios, 6, 98-107.

Comité de Integración Latino Europa - América (2015). Guía de buenas prácticas de gobernanza empresarial para las Pyme. Estudios Internacionales CILEA, 1.

Dawson, P. (1997). In at the deep end: Conducting processual research on organizational change. Scandinavian Journal of M anagement, 13, pp. 389-405. Recuperado de: http:/ / dx.doi.org/10.1016/s0956-5221(97)00025-0.

Ganga Contreras F. y Vera Garnica J. (2008). Gobierno corporativo: consideraciones y cimientos teóricos. Cuaderno de A dministración Bogotá.21.

García Gómez, M. (1994). Los mapas de riesgos. Concepto y metodología para su elaboración. Instituto Nacional de Seguridad e Higiene en el Trabajo (INSHT), Madrid.

Hernández Sampieri, R., Fernández Collado, C., y Baptista Lucio, P. (2010). M etodología de la investigación. México: McGraw Hill.

Holmstrom, B. (1979). Moral hazard and observability. Bell Journal of Economics, 10, 74-91.

Knight, F. H. (1921). Risk, U ncertainty, and Profit New York: Hart, Schaffner, and Marx.

Laski, F. (2013). Actualización del Modelo COSO sobre control interno: análisis sobre las Modificaciones, Innovaciones y Novedades. Profesional y Empre saria (D-G), 14.

Mantilla Blanco, S. y Blanco, S. (2005). A uditoría del Control Interno. Bogotá: Ecoe ediciones.

Martínez Carazo, P. (2006). El método de estudio de caso. Pensamiento y Gestión, 20.

Martínez Rodríguez, J. (2001). Métodos de Investigación Cualitativa. Silogismos de Investigación, 8 . 
Mertens, D. (2005). Research and evaluation in Education and Psychology: Integrating diversity with quantitative, qualitative, and mixed methods. California: Sage.

Oliveira, M., Maçada, A. y Goldoni, V. (2009). Forças e franquezas na aplicação do estudo de caso na área de sistemas de informação. Revista de G estao, 16.

PwC (2013). Control Interno - M arco Integrado. Resumen Ejecutivo. Instituto de Auditores Internos de España.

Rodríguez López, M., Piñeiro Sánchez, C. y Llano Monelos P. (2013). Mapa de Riesgos: Identificación y Gestión de Riesgos. Revista A tlántica de E conomía, 2. Finanzas y Sistemas de Información para la Gestión (FYSIG), Facultad Economía y Empresa, Universidad de A Coruña, España.

Taylor, S. (1998). Introducción a los métodos cual itativos deinvestigación la búsqueda de significados. Buenos Aires: Paidós.

Velezmoro La Torre, O. (2010). M odelo de Gestión de Riesgo 0 peracional en una Institución Financiera Peruana dentro de un Enfoque Integrado de Gestión de Riesgos. Pontificia Universidad Católica del Perú, Lima, Perú.

Yin, R. (1989). Case Study Research: D esign and M ethods. California: Ed. Sage.

(C) 2017 por los autores; licencia otorgada a la revista Escritos Contables y de Administración. Este artículo es de acceso abierto y distribuido bajo los términos y condiciones de una licencia Atribución-No Comercial 4.0 Internacional (CC BY-NC 4.0) de Creative Commons. Para ver una copia de esta licencia, visite https://creativecommons.org/licenses/by-nc/4.0/ 


\section{Anexo}

\subsection{A nexo I: Justificación de la calificación de riesgos identificados}

\begin{tabular}{|c|c|c|c|c|c|c|c|}
\hline $\begin{array}{c}\text { Código } \\
\text { del } \\
\text { Riesgo }\end{array}$ & Riesgo & $\begin{array}{l}\text { Probabilidad } \\
\text { de Ocurrencia }\end{array}$ & $\mathbf{P}$ & Impacto & I & $\begin{array}{l}\text { Calificación } \\
\text { del Riesgo }\end{array}$ & $\begin{array}{l}\text { Nivel de } \\
\text { Riesgo }\end{array}$ \\
\hline 14 & $\begin{array}{l}\text { Certificación } \\
\text { de importes } \\
\text { que difieren } \\
\text { de los factu- } \\
\text { rados. }\end{array}$ & $\begin{array}{l}\text { BAJA. Generalmente, las } \\
\text { tarifas del gas boca de } \\
\text { pozo poseen dos decima- } \\
\text { les, sólo se ha presentado } \\
\text { un caso con tres decima- } \\
\text { les. }\end{array}$ & 1 & $\begin{array}{l}\text { BAJO. La situación tiene } \\
\text { una explicación formal } \\
\text { sobre la limitación del } \\
\text { sistema. El área de Cuen- } \\
\text { tas a Pagar no abona } \\
\text { importes superiores al } \\
\text { facturado. }\end{array}$ & 1 & 1 & Aceptable \\
\hline 4 & $\begin{array}{l}\text { Retrasos en la } \\
\text { generación del } \\
\text { CM a tiempo } \\
\text { debido a otras } \\
\text { actividades } \\
\text { del sector }\end{array}$ & $\begin{array}{l}\text { MEDIA. Dado que el área } \\
\text { de Compras genera CM } \\
\text { de todas las áreas de la } \\
\text { compañía, en ocasiones } \\
\text { se producen demoras } \\
\text { por el desarrollo de otras } \\
\text { actividades, especial- } \\
\text { mente cuando existen } \\
\text { paradas de planta. }\end{array}$ & 3 & $\begin{array}{l}\text { ALTA. Imposibilidad de } \\
\text { librar el pago al provee- } \\
\text { dor en tiempo y forma, } \\
\text { posible generación de } \\
\text { intereses por mora. }\end{array}$ & 3 & 9 & Moderado \\
\hline 12 & $\begin{array}{l}\text { Retrasos en } \\
\text { el reenvío de } \\
\text { facturas a cer- } \\
\text { tificar. }\end{array}$ & $\begin{array}{l}\text { ALTA. No se revisa dia- } \\
\text { riamente la casilla de } \\
\text { correos / página web } \\
\text { donde los proveedores } \\
\text { envían la facturación. }\end{array}$ & 5 & $\begin{array}{l}\text { MEDIO. Dado que la } \\
\text { recepción de facturas es } \\
\text { una actividad periódica, } \\
\text { el impacto es moderado } \\
\text { ya que al no recibir los } \\
\text { documentos al día } 20 \text { de } \\
\text { cada mes se genera el } \\
\text { reclamo correspondiente. }\end{array}$ & 2 & 10 & $\begin{array}{l}\text { Inacepta- } \\
\text { ble }\end{array}$ \\
\hline 21 & $\begin{array}{l}\text { Interrupción } \\
\text { de la produc- } \\
\text { ción continua } \\
\text { por cortes en } \\
\text { el suministro } \\
\text { de gas natural. }\end{array}$ & $\begin{array}{l}\text { ALTA. Si bien durante los } \\
\text { dos últimos inviernos no } \\
\text { se produjeron cortes del } \\
\text { suministro, Argentina } \\
\text { aún se encuentra en crisis } \\
\text { energética, sólo inviernos } \\
\text { cálidos pueden evitar los } \\
\text { cortes. Dada la aleato- } \\
\text { riedad de dicha variable } \\
\text { y que no existen otros } \\
\text { mecanismos para supri- } \\
\text { mir la interrupción del } \\
\text { suministro, se considera } \\
\text { razonable una alta proba- } \\
\text { bilidad de ocurrencia. }\end{array}$ & 5 & $\begin{array}{l}\text { ALTA. Pérdida de pro- } \\
\text { ducción, posible incum- } \\
\text { plimiento de acuerdos } \\
\text { comerciales con clientes. }\end{array}$ & 3 & 15 & $\begin{array}{l}\text { Inacepta- } \\
\text { ble }\end{array}$ \\
\hline
\end{tabular}




\section{Laura Daima}

\begin{tabular}{|c|c|c|c|c|c|c|c|}
\hline $\begin{array}{c}\text { Código } \\
\text { del } \\
\text { Riesgo }\end{array}$ & Riesgo & $\begin{array}{l}\text { Probabilidad } \\
\text { de } 0 \text { currencia }\end{array}$ & $\mathbf{P}$ & Impacto & I & $\begin{array}{l}\text { Calificación } \\
\text { del Riesgo }\end{array}$ & $\begin{array}{l}\text { Nivel de } \\
\text { Riesgo }\end{array}$ \\
\hline 25 & $\begin{array}{l}\text { Políticas de } \\
\text { incentivo a la } \\
\text { producciónde } \\
\text { gas natural } \\
\text { con un hori- } \\
\text { zonte de corto } \\
\text { plazo. }\end{array}$ & $\begin{array}{l}\text { MEDIA. Dado que existe } \\
\text { una aceptación gene- } \\
\text { ralizada respecto a que } \\
\text { nos encontramos en una } \\
\text { situación de crisis ener- } \\
\text { gética, es posible que se } \\
\text { continúen con políticas } \\
\text { que incentiven a incre- } \\
\text { mentar la producción de } \\
\text { gas natural. En contrapo- } \\
\text { sición, se debe considerar } \\
\text { que las políticas depen- } \\
\text { den de gestiones guber- } \\
\text { namentales, las alternan- } \\
\text { cias de gobierno pueden } \\
\text { afectar o acentuar las } \\
\text { políticas, es por ello que } \\
\text { se considera razonable } \\
\text { evaluar al riesgo con una } \\
\text { probabilidad de ocurren- } \\
\text { cia media. }\end{array}$ & 3 & $\begin{array}{l}\text { ALTA. De no concretarse } \\
\text { las políticas que incen- } \\
\text { tiven a la producción, la } \\
\text { organización continúa } \\
\text { expuesta a cortes en el } \\
\text { suministro e incremento } \\
\text { de costos. }\end{array}$ & 3 & 9 & Moderado \\
\hline 30 & $\begin{array}{l}\text { Posible reduc- } \\
\text { ción/interrup- } \\
\text { ción del sumi- } \\
\text { nis tro por } \\
\text { crisis hídrica. }\end{array}$ & $\begin{array}{l}\text { MEDIA. Dado que desde } \\
\text { hace varios años la cota } \\
\text { del dique se encuentra } \\
\text { por encima del nivel de } \\
\text { alerta }(158 \mathrm{~mm}) \text { y que el } \\
\text { mismo depende de un } \\
\text { factor aleatorio, sin posi- } \\
\text { bilidad de gestión sobre } \\
\text { el mismo (factor climá- } \\
\text { tico), se considera razo- } \\
\text { nable evaluar al riesgo } \\
\text { con una probabilidad } \\
\text { media. }\end{array}$ & 3 & $\begin{array}{l}\text { ALTA. Pérdida de pro- } \\
\text { ducción, potenciales } \\
\text { incumplimientos de } \\
\text { acuerdos comerciales con } \\
\text { clientes. }\end{array}$ & 3 & 9 & Moderado \\
\hline
\end{tabular}

Fuente: elaboración propia. La tabla completa de "Justificación de la calificación de riesgos identificados" puede ser solicitada a la autora (daimalaura@hotmail.com). 


\subsection{Anexo II: A cciones propuestas para los riesgos identificados}

\begin{tabular}{|c|c|c|c|c|c|}
\hline $\begin{array}{l}\text { Código } \\
\text { Riesgo }\end{array}$ & Riesgo & $\begin{array}{l}\text { Calificación } \\
\text { del Riesgo }\end{array}$ & $\begin{array}{l}\text { Nivel de } \\
\text { Riesgo }\end{array}$ & $\begin{array}{l}\text { Tipo de } \\
\text { Riesgo }\end{array}$ & Acción propuesta \\
\hline 14 & $\begin{array}{l}\text { Certificación de } \\
\text { importes que } \\
\text { difieren de los } \\
\text { facturados. }\end{array}$ & 1 & Aceptable & Interno & $\begin{array}{l}\text { Se obtuvo la respuesta formal por parte } \\
\text { del área de Sistemas en donde se establece } \\
\text { que el software corporativo fue definido } \\
\text { sólo con dos decimales para expresar las } \\
\text { tarifas. De todas formas, por más que la } \\
\text { certificación de las facturas se realice por } \\
\text { importes superiores a los facturados, } \\
\text { el sector de Cuentas a Pagar, no abona } \\
\text { importes superiores a los liquidados por } \\
\text { el proveedor. }\end{array}$ \\
\hline 4 & $\begin{array}{l}\text { Retrasos en la } \\
\text { generación del } \\
\text { CM a tiempo } \\
\text { debido a otras } \\
\text { actividades del } \\
\text { sector. }\end{array}$ & 9 & Moderado & Interno & $\begin{array}{l}\text { Dado que la mayor cantidad de } \mathrm{CM} \text { se gene- } \\
\text { ran a principio de año, se sugiere que con } \\
\text { anticipación se comunique por escrito al } \\
\text { área de Compras qué se requerirá de ella, de } \\
\text { manera que ésta pueda planificar sus tareas. }\end{array}$ \\
\hline 12 & $\begin{array}{l}\text { Retrasos en el } \\
\text { reenvío de fac- } \\
\text { turas a certificar. }\end{array}$ & 10 & Inaceptable & Interno & $\begin{array}{l}\text { A partir de los contactos comerciales } \\
\text { propuestos por los proveedores en los } \\
\text { contratos celebrados, se sugiere solicitar } \\
\text { al mismo, que notifique vía email al Ana- } \\
\text { lista de Insumos Estratégicos y Control } \\
\text { de Gestión cuándo la factura fue enviada } \\
\text { a la organización, de manera de poder } \\
\text { reclamar su reenvío al sector de Cuentas } \\
\text { a Pagar y evitar los retrasos. }\end{array}$ \\
\hline
\end{tabular}

Interrupción de

la producción

21 continua por cortes en el suministro de gas natural.
Al ser un riesgo externo, la gestión sobre el mismo no podrá ser integral. Adicionalmente, Argentina se encuentra en una crisis energética, con lo cual la organización depende principalmente de cuestiones climáticas que puedan reducir/eliminar los cortes de suministro. De todas formas, es relevante continuar con la presencia en el Comité de Emergencia del ENARGAS ya que es un instrumento que permite anticiparse en el conocimiento de posibles cortes o restricciones y poder planificar de la mejor manera posible el escenario de producción y los compromisos asumidos con clientes. 


\section{Laura Daima}

\begin{tabular}{|c|c|c|c|c|c|}
\hline $\begin{array}{l}\text { Código } \\
\text { Riesgo }\end{array}$ & Riesgo & $\begin{array}{c}\text { Calificación } \\
\text { del Riesgo }\end{array}$ & $\begin{array}{l}\text { Nivel de } \\
\text { Riesgo }\end{array}$ & $\begin{array}{l}\text { Tipo de } \\
\text { Riesgo }\end{array}$ & Acción propuesta \\
\hline
\end{tabular}

Políticas de incentivo a la 25 producción de gas natural con un horizonte de corto plazo.
No existe gestión sobre dicho riesgo, sólo se puede mencionar que la participación de la organización en asociaciones tales como ACIGRA le permite estar actualizada con respecto a la legislación vigente y a los cambios que acontecen en la misma.
Posible reducción/interrup30 ción del suministro por crisis hídrica.
9

Moderado

Externo
Es un riesgo no gestionable por la organización, sobre el cual se podría proponer el monitoreo de la cota del Dique, como la posible participación en grupos científicos que busquen potenciales fuentes alternativas para el suministro de agua a la ciudad de Bahía Blanca.

Fuente: elaboración propia. La tabla completa de "Acciones propuestas para los riesgos identificados" puede ser solicitada a la autora (daimalaura@hotmail.com). 


\section{ARTÍCULOS \\ DE INVESTIGACIÓN CIENTÍFICA}





\section{El DifERIMIENTO DEL IMPUESTO A LAS GANANCIAS}

\section{THE DEFERRAL OF INCOME TAX}

Hugo Ricardo Arreghini ${ }^{1}$

Fecha de recepción: 06/05/2019

Fecha de aceptación: 13/08/2019

\section{Resumen}

La explicación del resultado fiscal, aunque está fundamentada en información procedente de la normativa contable vigente, hace una interpretación particular de los criterios que esas reglas adoptan. De tal modo, es natural que se observen diferencias en el cálculo del impuesto a la renta, según se haga con una u otra metodología. Sin embargo, la supremacía en la aplicación del criterio fiscal que el contribuyente debe aceptar, le exige la adopción de un especial entendimiento, cuya manifestación tácita de acatamiento ha sido dada en función de la protección que la persona jurídica -física o ideal- recibe del Estado que la reconoce. Esta circunstancia es decisiva para comprender que el impuesto solo se define por la forma en que el Estado percibe el beneficio patrimonial que genera dicho impuesto. Por tal motivo, cualquier otra forma conceptual que permita originar diferimientos y consecuentes resultados, activos o pasivos, no tendría sentido.

Pal abras clave: persona jurídica, ente económico, activo diferido, pasivo diferido, beneficio económico participado.

1 Universidad del Centro de la Provincia de Buenos Aires (UNICEN), Facultad de Ciencias Económicas, Profesor Emérito; Universidad de Buenos Aires (UBA), Facultad de Ciencias Económicas, Profesor Consulto. E-mail: harreghini@gmail.com 